\title{
Relación de aguas superficiales y subterráneas en el área del lago Chungará y lagunas de Cotacotani, norte de Chile: un estudio isotópico
}

\author{
Christian Herrera
}

Juan José Pueyo

Alberto Sáez

Blas L. Valero-Garcés
Departamento de Ciencias Geológicas, Universidad Católica del Norte, Casilla 1280, Antofagasta, Chile cherrera@ucn.cl

Departamento de Geoquímica, Petrología y Prospección Geológica, Facultad de Geología, Universidad de Barcelona, E-08028 Barcelona, España jjpueyo@ub.edu

Departamento Estratigrafía, Paleontología y Geociencias Marina, Grupo de Geodinámica y Análisis de Cuenca, Universidad de Barcelona, E-08028 Barcelona, España a.saez@ub.edu

Instituto Pirenaico de Ecología, Consejo Superior de Investigaciones Científicas, Zaragoza, España blas@ipe.csic.es

RESUMEN

El lago Chungará y las lagunas de Cotacotani corresponden a cuerpos de aguas superficiales localizados al noroeste de la Cuenca del Lauca, en el Altiplano del norte de Chile. Todas las aguas superficiales y subterráneas tienen una salinidad baja a moderada con conductividades eléctricas variables entre 48,7 y $3090 \mu \mathrm{S} / \mathrm{cm}$. Los lagos están conectados a acuíferos situados en los flancos de los edificios volcánicos próximos, así como en los depósitos de brechas de avalancha del volcán Parinacota. Las composiciones isotópicas de $\delta^{18} \mathrm{O}$ y $\delta \mathrm{D}$ y su relación con las concentraciones de cloruro de las aguas del lago Chungará, lagunas de Cotacotani, manantiales afluentes y del río Chungará, demuestran que: a. las aguas del lago Chungará presentan una composición química e isotópica homogénea tanto en la horizontal como en la vertical, lo que indica una buena mezcla de las aguas en el lago; b. una parte importante de la recarga hídrica que alimenta las lagunas de Cotacotani procede de aguas del lago Chungará, canalizada a través de un flujo lateral subterráneo y c. el agua subterránea que da origen a los manantiales de la zona tiene su recarga principal en las precipitaciones que se registran durante los meses de primavera-verano (octubre-marzo). Los altos contenidos de tritio $\left({ }^{3} \mathrm{H}\right)$ medidos en las aguas de los manantiales del sector indican que existe una recarga actual (durante los últimos decenios) al sistema acuífero. La aplicación de modelos de parámetro agregado para la interpretación del tiempo de residencia del agua en el acuífero indica que el modelo de flujo de pistón es el que mejor se ajusta a las características isotópicas de estas aguas subterráneas.

Palabras claves: Lago Chungará, Lagunas de Cotacotani, Aguas subterráneas, Recarga, Isótopos estables, Tritio, Chile. 
Relation of surface and underground waters in Chungará and Cotacotani lake districts, northern Chile: an isotopic study. Lake Chungará and Cotacotani lake districts are surface water bodies located to the northwest of Lauca Basin in the northern Chilean Altiplano. Surface and underground waters show low to moderate saline content and an electrical conductivity in the range of 48.7 to $3090 \mu \mathrm{S} / \mathrm{cm}$. The lakes are related to a system of aquifers on the nearby volcano flanks and debris avalanche deposits of Parinacota volcano. On the basis of $\delta^{18} \mathrm{O}$ and $\delta \mathrm{D}$ isotopic composition and its correlation with the chloride content in Chungará and Cotacotani lake, spring, and Chungará river waters it is demonstrated that: a. Lake Chungará's waters show vertical and horizontal homogeneous isotopic composition, which indicates a good mixture of waters in the lake; b. an important part of the Cotacotani lake recharge feeding come from Lake Chungará, that flows laterally as groundwater; c. the groundwater that feeds the springs of the area has its main recharge in the spring-summer (October-March) precipitation. The high content of tritium $\left({ }^{3} \mathrm{H}\right)$ measured in spring waters of the area suggested a very recent recharge (last decades) of the aquifer system. The application of lumped parameter models to interpret the water residence time in the aquifer indicates that the piston flow model shows the best fit to the isotopic composition of Chungará-Cotacotani groundwater.

Key words: Lake Chungará, Cotacotani Lakes, Groundwater, Recharge, Stable Isotopes, Tritium, Chile.

\section{INTRODUCCIÓN}

El Desierto de Atacama sensu lato es una de las regiones más áridas del mundo. Mientras que en la zona costera del norte de Chile las precipitaciones son prácticamente nulas ( $1 \mathrm{~mm}$ de promedio anual) éstas aumentan progresivamente hacia la zona altiplánica, donde alcanzan los $350 \mathrm{~mm}$ anuales. La extrema aridez de la región está condicionada por la existencia de un anticiclón permanente en el Océano Pacífico, frente a las costas del norte de Chile y por la Cordillera de los Andes que constituye una importante barrera orográfica para los frentes de humedad que proceden del Océano Atlántico a través de la Cuenca Amazónica.

El lago Chungará y las lagunas de Cotacotani se ubican en la parte nororiental de la Región de Tarapacá (Chile), en el interior del Parque Nacional Lauca (Fig. 1). El clima imperante en el sector es estepario de altura y se caracteriza por ser extremadamente seco la mayor parte del año, con excepción del período comprendido entre los meses de diciembre a marzo, cuando se producen las mayores precipitaciones (Montti y Henríquez, 1970). Este patrón de precipitación de verano es conocido informalmente como 'Invierno Altiplánico' o 'Invierno Boliviano' y representa la humedad proveniente del Océano Atlántico. La precipitación media anual en la zona del lago Chungará durante los últimos 35 años es de $331 \mathrm{~mm}$, de los cuales $300 \mathrm{~mm}$ caen entre los meses de noviembre y abril (Dirección General de Aguas (DGA), 1987).
Los primeros estudios de las aguas en la zona de Chungará-Cotacotani tuvieron como objeto el control de la calidad química de las mismas para evaluar su uso en regadío (Mladinic et al., 1984). Risacher et al. (2003) estudiaron la hidroquímica de las aguas en todas las cuencas del Altiplano chileno con especial énfasis en las aguas de lagos salinos, aunque también proporcionaron datos sobre las subcuencas del lago Chungará y las lagunas de Cotacotani. Dorador et al. (2003), en un estudio reciente sobre microfauna del lago Chungará, proporcionan datos relativos a las variaciones temporales de parámetros físicos y químicos de las aguas del lago Chungará.

Aparte de los trabajos hidroquímicos mencionados, no hay estudios hidrogeológicos previos en la zona. No hay pozos o sondeos que permitan conocer el sistema de circulación de las aguas subterráneas, como tampoco estudios sobre la relación de los cuerpos de agua superficial con las aguas subterráneas. Este desconocimiento hidrogeológico ha generado problemas en la utilización de los recursos hídricos en la zona. Así, en los años setenta se intentó explotar el agua del lago Chungará, a través de un bombeo intensivo, con objeto de abastecer de agua dulce la actividad agrícola que se desarrolla en el valle de Azapa. No obstante, esta explotación fue rápidamente detenida a causa de un descenso significativo del nivel del agua en el lago, que comenzó a afectar la flora y fauna del lugar. 


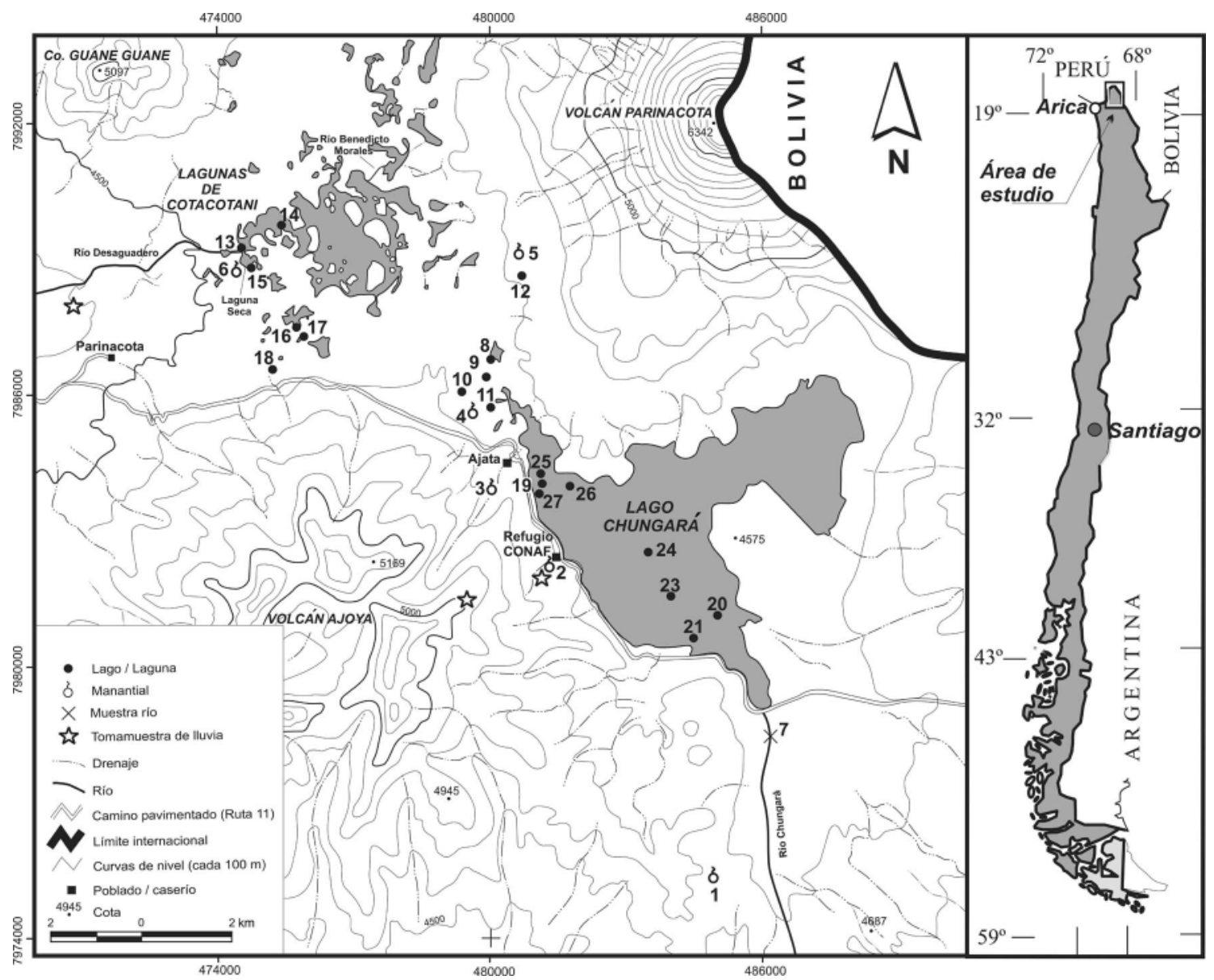

FIG. 1. Mapa de ubicación de los manantiales, río Chungará, lagunas de Cotacotani y lago Chungará.

Este estudio tiene como objetivo establecer hipótesis fundadas sobre el sistema de circulación de las aguas subterráneas en el área de Chungará-Cotacotani y su relación con las aguas superficiales, mediante la utilización de técnicas isotópicas ambientales. Ade- más, se pretende establecer el tiempo de residencia del agua en los lagos con objeto de su utilización en modelos paleolimnológicos y paleoclimáticos que se realizan sobre el conjunto de los sistemas lacustres en los Andes Centrales.

\section{METODOLOGÍA}

La caracterización química e isotópica de las aguas de los manantiales, lagunas de Cotacotani y lago Chungará, se realizó en tres campañas de muestreo: enero del 2002, noviembre del 2002 y enero del 2004. En la primera campaña se muestrearon principalmente los manantiales y algunas de las lagunas de Cotacotani. En la segunda se muestrearon nuevamente los manantiales y las lagunas de Cotacotani, y se realizó un muestreo sistemático (tanto en superficie como en profundidad) de las aguas del lago Chungará. La tercera campaña tuvo como objetivo conocer la variabilidad en la composición química e isotópica de las aguas de las lagunas y manantiales. 


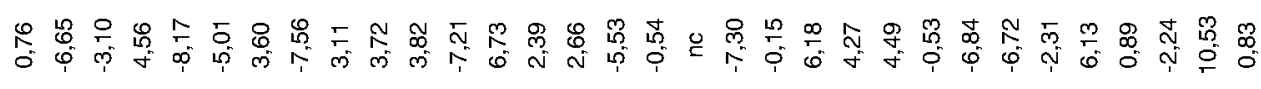

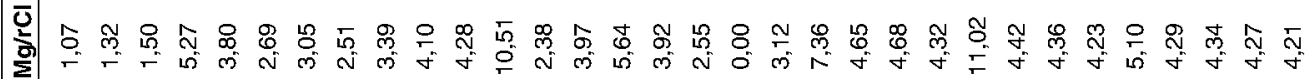

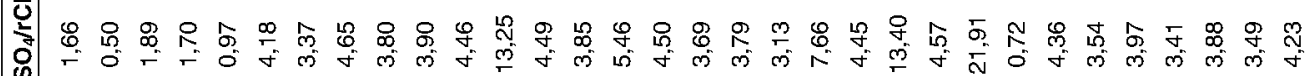

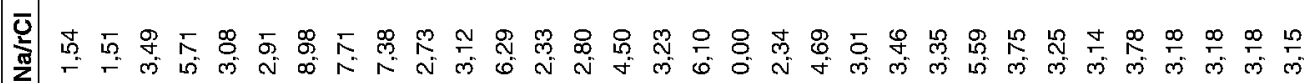

क人

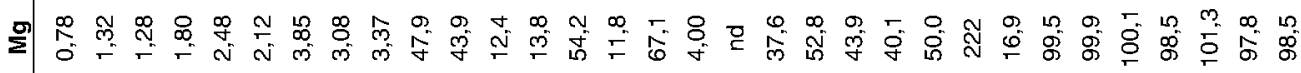

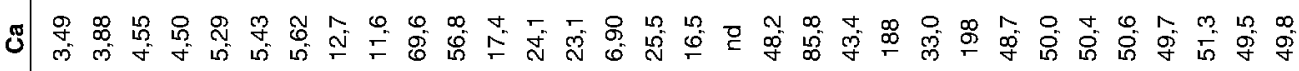

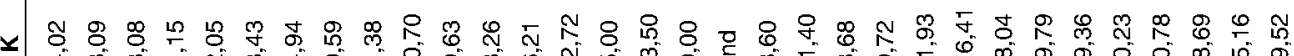

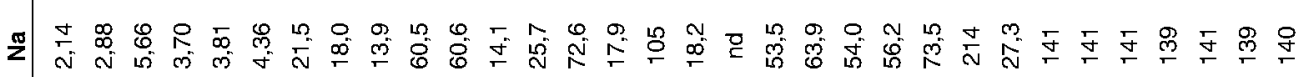

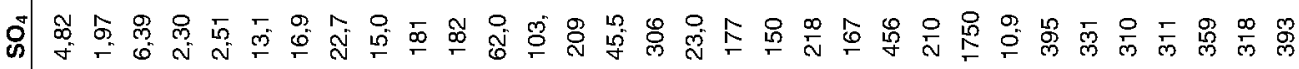

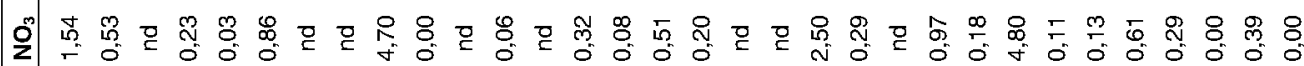

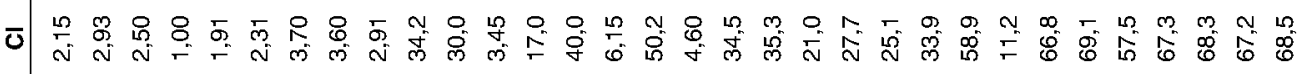

旁

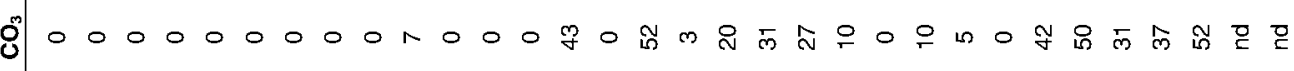

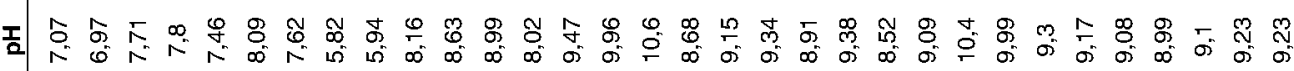

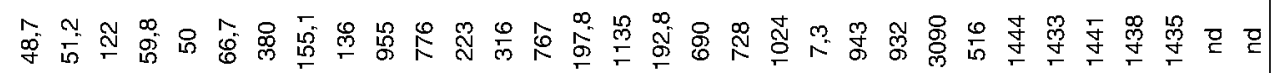

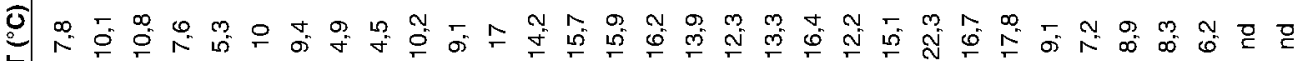

ㄸํㄴ

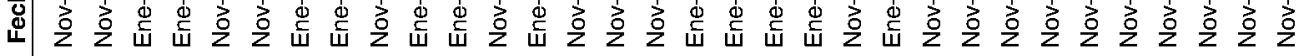

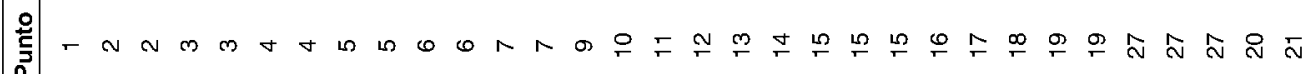


Las variables medidas in situ fueron la conductividad eléctrica, el $\mathrm{pH}$, la temperatura y la alcalinidad del agua. Se analizaron químicamente los componentes mayoritarios de 32 muestras de agua (Tabla 1). Los aniones fueron determinados mediante cromatografía iónica $\left(\mathrm{Cl}, \mathrm{SO}_{4}{ }^{2-}, \mathrm{NO}_{3}{ }^{-}\right)$y volumetría $\left(\mathrm{HCO}_{3}{ }^{-}\right)$, y los cationes mediante espectrometría de emisión de plasma (ICP-OES). Los análisis se realizaron a partir de muestras filtradas $(0,45 \mu \mathrm{m})$ en el momento del muestreo que, para el caso de los cationes, fue además acidulada ( $\left.1 \% \mathrm{HNO}_{3}\right)$.

En total se obtuvieron 43 muestras de agua para análisis de $\delta^{18} \mathrm{O}$ y $\delta \mathrm{D}$ (Tablas 2 y 3 ), de ellas 12 corresponden a muestras de manantiales, 19 a muestras del lago Chungará y 11 a muestras de las lagunas de Cotacotani. A éstas se suman 5 muestras de precipitación acumulada, obtenidas los meses de marzo de 2002 y noviembre de 2002. También fueron obtenidas 9 muestras de agua para análisis de tritio en algunos manantiales y lagunas del sector.

Las muestras de precipitación fueron recogidas en recipientes preparados para recuperar tanto la depositación húmeda como la seca. En los recipientes se vertió vaselina líquida para evitar los efectos de evaporación en las muestras durante los períodos entre las recolecciones. También se tomaron, en el momento de su caída (enero de 2004), dos muestras de granizo en la zona de las lagunas de Cotacotani.

Las muestras tomadas para análisis de $\delta^{18} \mathrm{O}$ y $\delta \mathrm{D}$ fueron almacenadas en botellas de polietileno de 50 $\mathrm{mL}$. Las muestras obtenidas para análisis de tritio se almacenaron en botellas de polietileno de doble tapón de 1 litro. Los análisis de $\delta^{18} \mathrm{O}$ y $\delta \mathrm{D}$ fueron realizados en los laboratorios de los Servicios Científico-Técnicos de la Universidad de Barcelona. Para determinación de $\delta^{18} \mathrm{O}$, se aplicó el método convencional de equilibrar con $\mathrm{CO}_{2}$, mientras que para la determinación de $\delta$ D, se equilibró con $\mathrm{H}_{2}$ en presencia de platino como catalizador. La precisión es de $0,1 \%$ para las medidas de $\delta^{18} \mathrm{O}$ y de $1,5 \%$ o para $\delta \mathrm{D}$. Las determinaciones de tritio se realizaron en el Servicio de Radioactividad Ambiental de la Universidad Autónoma de Barcelona.

Para la estimación del tiempo de residencia del agua en el acuífero se utilizó el código MULTIS (Ritchter et al., 1992), desarrollado para la interpretación de datos isotópicos ambientales y radioactivos en estudios hidrogeológicos. Los dos modelos extremos utilizados por este programa son el exponencial y el de flujo de pistón. El código también permite trabajar con distintas combinaciones en serie y en paralelo de estos modelos. Los cálculos que efectúa el código se pueden realizar tanto en forma directa como inversa. En forma directa se obtienen diferentes funciones teóricas de salida para los distintos parámetros proporcionados, mientras que en forma inversa permite obtener los parámetros que mejor ajustan la función de salida teórica a la real.

TABLA 2. COMPOSICIÓN ISOTÓPICA DE LAS PRECIPITACIONES DEL ÁREA DE ESTUDIO.

\begin{tabular}{|c|c|c|c|c|c|}
\hline Punto & Fecha & Altitud & $\begin{array}{c}\delta^{18} \mathrm{O}_{\text {smow }} \\
(\% \circ)\end{array}$ & $\begin{array}{c}\delta D_{\text {smow }} \\
(\% \circ)\end{array}$ & $\begin{array}{c}d \\
(\%)\end{array}$ \\
\hline Parinacota & Mar-2002 & 4.380 m s.n.m. & $-15,03$ & $-108,9$ & 11,34 \\
\hline Lago Chungará & Mar-2002 & 4.590 m s.n.m. & $-15,93$ & $-117,5$ & 9,94 \\
\hline Vn. Ajoya & Mar-2002 & 5.000 m s.n.m. & $-19,40$ & $-132,3$ & 22,90 \\
\hline Parinacota & Nov-2002 & 4.380 m s.n.m. & $-4,35$ & $-16,5$ & 18,30 \\
\hline Lago Chungará & Nov-2002 & 4.590 ms.n.m. & $-16,27$ & $-108,7$ & 21,46 \\
\hline $\begin{array}{c}\text { Cotacotani } \\
\text { (granizo) }\end{array}$ & Ene-2004 & 4.550 m s.n.m. & $-14,32$ & $-91,6$ & 22,96 \\
\hline $\begin{array}{c}\text { Cotacotani } \\
\text { (granizo) }\end{array}$ & Ene-2004 & 4.550 m s.n.m. & $-14,62$ & $-91,8$ & 25,16 \\
\hline
\end{tabular}




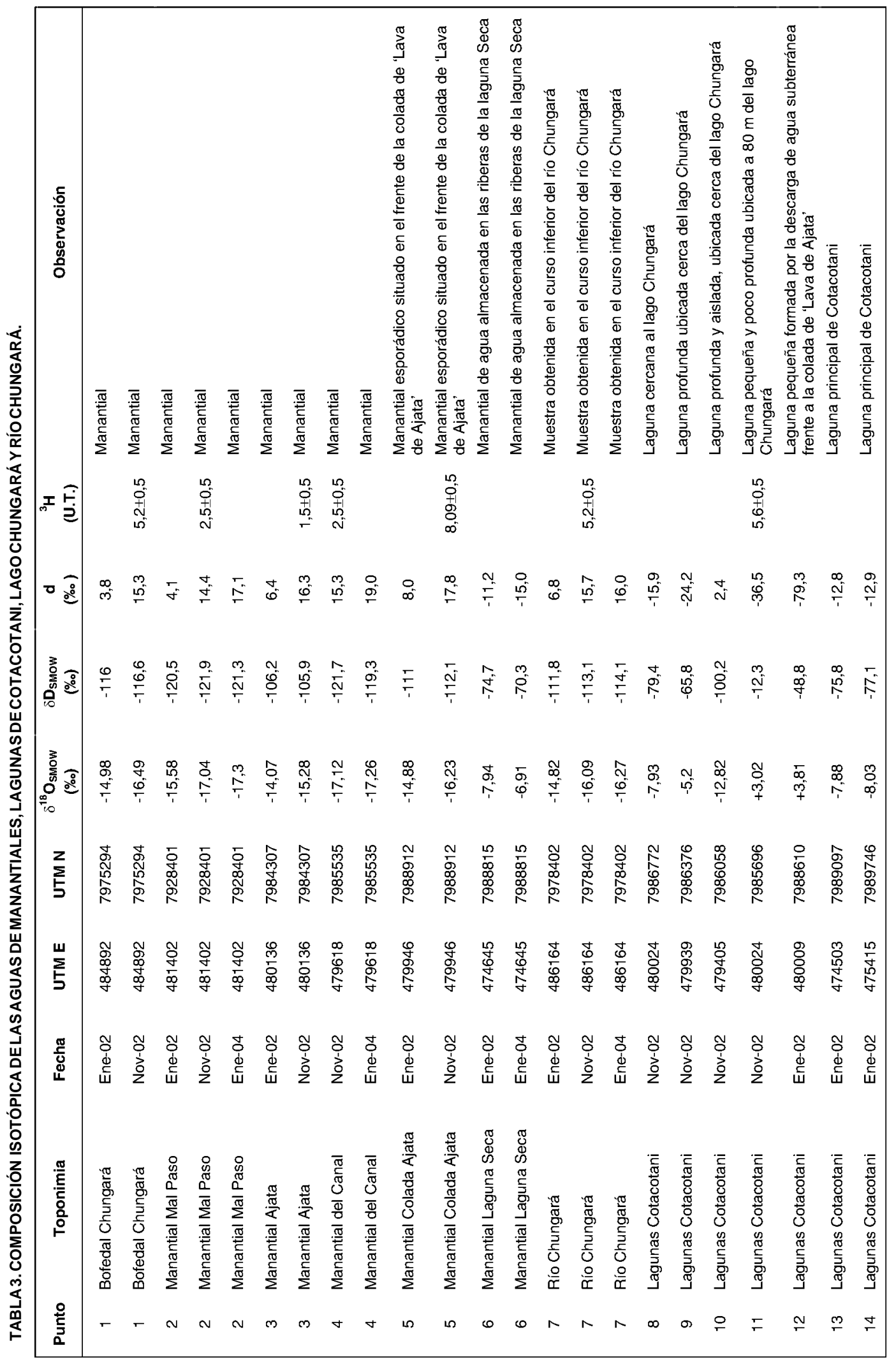




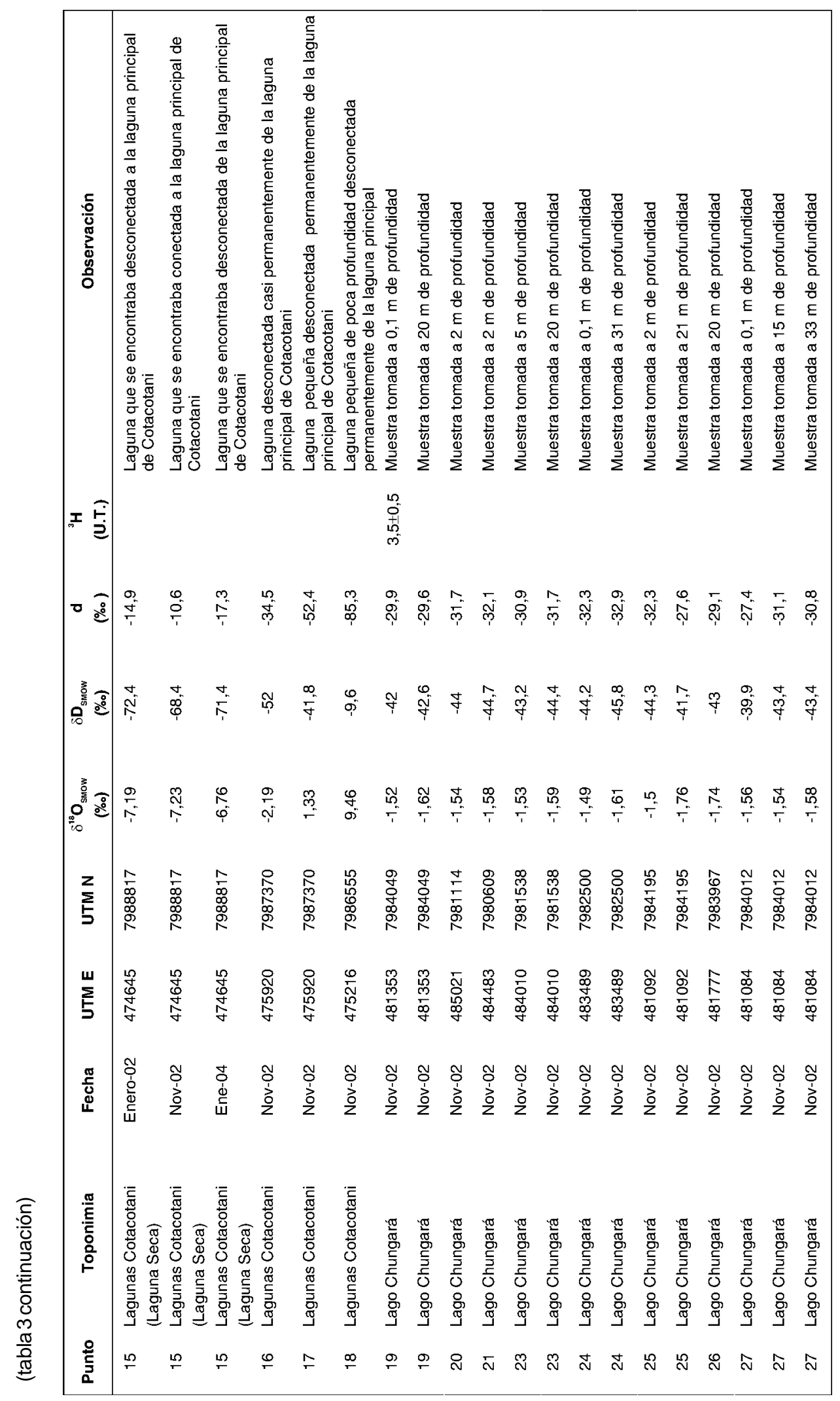




\section{MARCO GEOLÓGICO}

El área del lago Chungará y de las lagunas de Cotacotani se caracteriza por la intermitente actividad volcánica desarrollada desde el Mioceno hasta la actualidad (Katsui y González-Ferrán, 1968; Wörner et al., 1988; Clavero et al., 2002). En la proximidad de los lagos existen tres importantes edificios volcánicos (los volcanes Parinacota, Ajoya y Quisiquisini; Fig. 2) que se levantaron sobre un basamento ignimbrítico de edad miocena que aflora al sur y este del lago Chungará (Wörner et al., 1988).

El volcán Parinacota es un estratovolcán de forma cónica simétrica, que alcanza una altitud de 6.342 m s.n.m., y muestra una buena conservación de las coladas de lava y domos. Las coladas de lava más distales del flanco sur del volcán corresponden al límite norte del lago Chungará. Una serie de depósitos de brechas (debris avalanche) originados por colapso de este volcán se localizan al oeste del edificio volcánico y conforman el lugar sobre el que se sitúan las lagunas de Cotacotani (Clavero et al., 2002, Fig. 2). Las coladas de lava más recientes se localizan en los flancos sur y oeste del edificio volcánico, y corresponden a lavas de composición andesítica-basáltica de color gris oscuro y textura afanítica ('lava de Ajata'). La buena conservación de las coladas de lava se debe, posiblemente, a que una parte importante del último edificio volcánico comenzó a ser construido hace unos 18.000 años (Wörner et al., 1988).

El volcán Ajoya tiene edad miocena, se localiza en la parte sur del área de estudio y presenta un edificio volcánico medianamente erosionado (Fig. 2). Aunque se logra diferenciar parte de un antiguo cráter en su cima, no se individualizan claramente las coladas de lava que lo constituyen. Las lavas son principalmente de composición andesítica, de color gris, con texturas porfídicas con fenocristales de plagioclasa, hornblenda y piroxeno (Katsui y González-Ferrán, 1968).

El volcán Quisiquisini tiene edad pleistocena, se sitúa al este del lago Chungará, y al igual que el volcán Ajoya presenta un edificio volcánico medianamente erosionado donde no se diferencian con claridad las distintas coladas de lava que lo constituyen. El volcán está compuesto principalmente por lavas y tobas de composición andesítica (Katsui y González-Ferrán, 1968).

\section{CARACTERIZACIÓN DEL SISTEMA HIDROLÓGICO DEL ÁREA DE CHUNGARÁ-COTACOTANI}

El lago Chungará es un cuerpo de agua dulce situado a $4.544 \mathrm{~m}$ s.n.m., con una superficie de 21,5 $\mathrm{km}^{2}$ y una profundidad máxima de 36 a $40 \mathrm{~m}$ (Valero et al., 2003). El lago se alimenta superficialmente por el río Chungará, que desemboca en el margen suroriental, con un caudal que varía entre 0,3 y $0,5 \mathrm{~m}^{3} \mathrm{~s}^{-1}$ (Dorador et al., 2003). Además, el lago recibe aportes superficiales de una serie de manantiales situados en las laderas de los volcanes que rodean el lago. Dado que en la zona de estudio no se han realizado perforaciones, no se dispone de datos de permeabilidad y de gradiente hidráulico para estimar los aportes de agua subterránea que alimentan al lago Chungará. El volumen promedio del agua almacenada en el lago es de 400 hm $^{3}$ (Mühlhauser et al., 1995), y la evaporación media potencial anual en el lago de $1.230 \mathrm{~mm}$ (Risacher et al., 1999). Teniendo en cuenta sólo la descarga anual por evaporación en el lago (aproximadamente $26 \mathrm{hm}^{3} / \mathrm{año}$ ), se puede estimar un tiempo medio de residencia del agua en el lago de aproxima- damente 15 años. Por otro lado, deben considerarse las descargas subterráneas de las aguas del lago, las cuales fluyen por un depósito de brechas (originadas por colapso del volcán Parinacota), que serán estimadas en este trabajo mediante la aplicación de indicadores isotópicos.

Las lagunas de Cotacotani forman un complejo sistema de cuerpos de agua, algunos de ellos desconectados entre sí, situado al noroeste del lago Chungará. El nivel medio de sus aguas se sitúa a $4.526 \mathrm{~m}$, es decir $18 \mathrm{~m}$ por debajo del nivel del agua del lago Chungará. Las lagunas están separadas del lago por una franja de brechas volcánicas, generadas durante un evento explosivo holoceno que colapsó un antiguo edificio del actual volcán Parinacota (Clavero et al., 2002, 2004). Estos depósitos están formados por bloques de lava de composición andesítica y riolítica que, en algunos casos, pueden tener varios metros de diámetro y que, en general, se encuentran distribuidos de forma caótica. En el conjunto de las lagunas de 


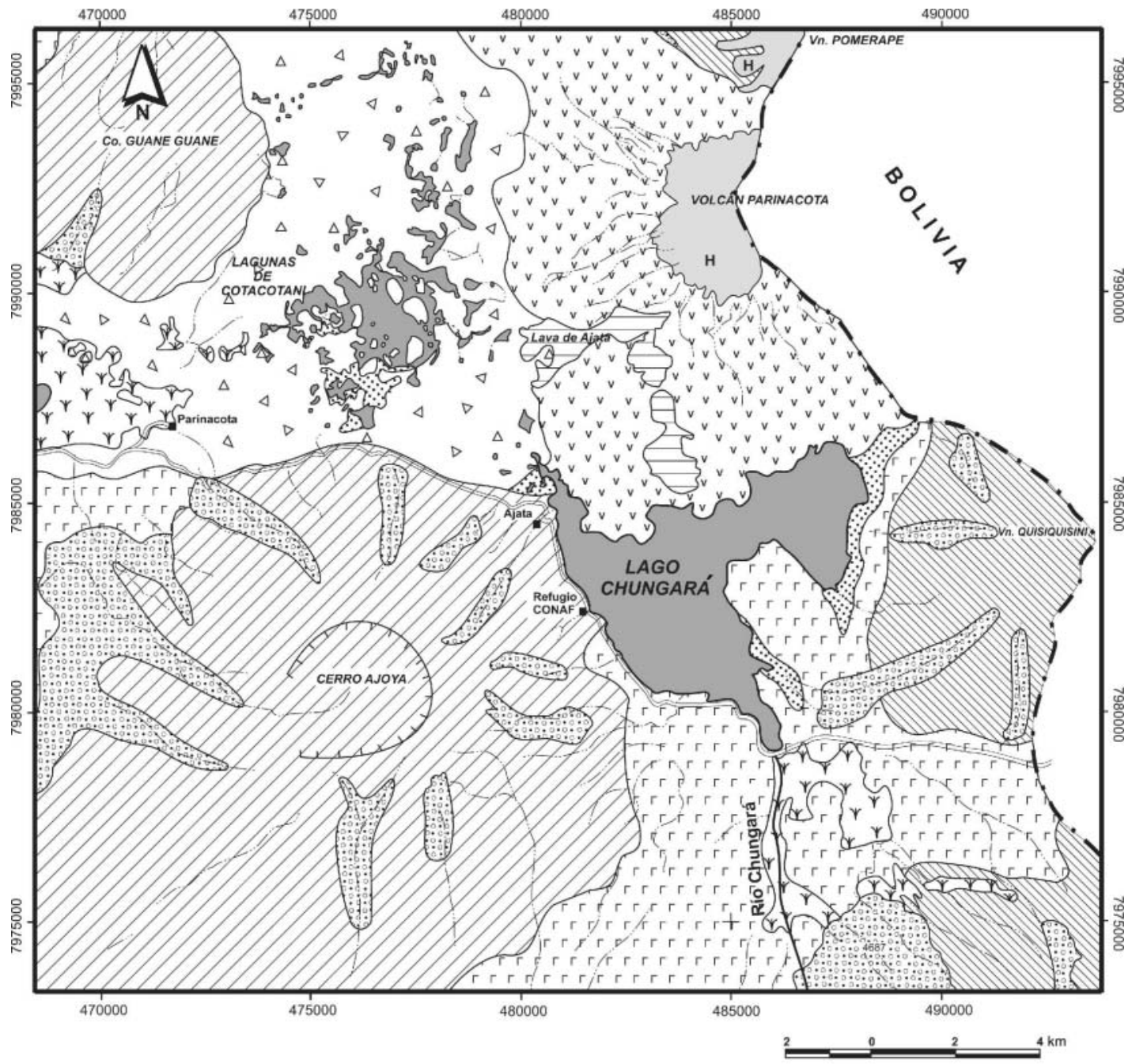

\section{Unidades Volcánicas}

Holoceno Superior

Flujo Ajata, andesita basáltica

v v v Pleistoceno

Vn. Parinacota. Lavas andesiticas, domos

riolíticos, depósitos de ceniza y pómez

Plioceno - Pleistoceno

Flujos de composición andesitica a riolitica

\section{Mioceno}

Complejo volcánico andesítico a dacítico

Mioceno

Basamento ignimbritico

\section{Unidades Sedimentarias}

$\because \because \because$ Holoceno Superior

Sedimentos no consolidados

Holoceno

Depósitos brechosos de colapso volcánico

Cantos de lava andesiticas y rioliticas

Pleistoceno

Morrenas y depósitos fluvio/glaciales

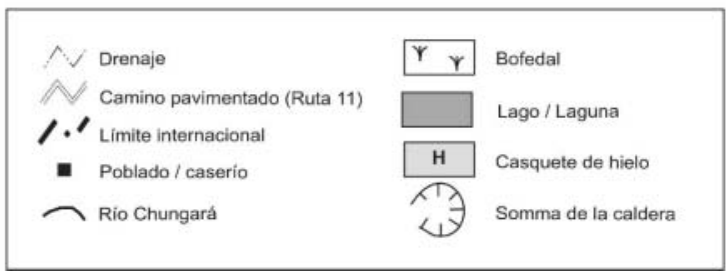

FIG. 2. Mapa geológico simplificado del área del lago Chungará y las lagunas de Cotacotani (modificado de Katsui y González-Ferrán, 1968; Clavero et al., 2002; SERNAGEOMIN, 2002) 
Cotacotani se reconoce una gran laguna principal y otras de menor tamaño. La laguna principal abarca una superficie aproximada de $5,2 \mathrm{~km}^{2}$ que, durante los períodos de menor aporte, reduce su superficie de agua libre a unos $4,1 \mathrm{~km}^{2}$. La profundidad máxima de esta laguna es de $20 \mathrm{~m}$. Uno de sus tributarios superficiales más importantes es el río Benedicto Morales, situado en el extremo noreste de la laguna principal y cuyas aguas provienen de surgencias de manantiales situados en la parte nororiental del volcán Parinacota (Klohn, 1972; Fig. 1). Durante los períodos de nivel de agua bajo, un conjunto de lagunas de menor tamaño quedan aisladas de la laguna principal de Cotacotani, destacando la laguna Seca que tiene una profundidad máxima de $8 \mathrm{~m}$ cuando está conectada a la laguna principal de Cotacotani, y de $1 \mathrm{~m}$ cuando queda aislada. En la vecindad de la laguna principal de Cotacotani existen algunas lagunas de menor tamaño que están permanentemente desconectadas de la misma. Las lagunas de Cotacotani tienen un desagüe superficial hacia el bofedal de Parinacota a través de un umbral rocoso, con un caudal medio de $0,44 \mathrm{~m}^{3} \mathrm{~s}^{-1}$ (DGA, 1987), que recibe el nombre de río Desaguadero y da origen al río Lauca (Fig.1).

\section{MARCO HIDROQUÍMICO DE LAS AGUAS SUPERFICIALES Y SUBTERRÁNEAS}

Se muestrearon y analizaron las aguas superficiales y subterráneas del área del lago Chungará y las lagunas de Cotacotani (Tabla 1). La calidad de los resultados analíticos se ha evaluado mediante el cálculo del error porcentual para todos los análisis químicos (excepto para aquellos en los que faltaba el análisis de algún electrolito) según la siguiente expresión (Custodio y Llamas, 1983):

$$
\operatorname{error}(\%)=200 \frac{\sum c a t-\sum a n}{\sum c a t+\sum a n}
$$

La mayoría de las muestras presentan errores inferiores a $8 \%$. Considerando que la mayoría de las muestras tienen conductividades eléctricas inferiores a $500 \mu \mathrm{S} / \mathrm{cm}$, son tolerables errores de hasta $8 \%$ (Custodio y Llamas, 1983), aunque en este trabajo se ha considerado una muestra con un $10 \%$ de error.

Una primera aproximación a la composición química de las aguas superficiales y subterráneas indica una baja a moderada mineralización de las aguas, con conductividades eléctricas variables entre 48,7 y 3090 $\mu \mathrm{S} / \mathrm{cm}$. Las aguas de los distintos manantiales delárea de estudio tienen temperaturas comprendidas entre los 4,5 y $10,8^{\circ} \mathrm{C}$ y conductividades eléctricas bajas, entre 48,7 y $955 \mu \mathrm{S} / \mathrm{cm}$. Las temperaturas más bajas fueron medidas en el manantial 5 ubicado en el frente de la colada de 'Lava de Ajata', lo que hace suponer que la recarga que da origen a las aguas de este manantial se produce en cotas altas, donde las temperaturas de las aguas de infiltración son más bajas. Todas las aguas de los manantiales son del tipo bicarbonatado-cálcico con contenidos variables de sodio, sulfato, magnesio y potasio (Ordenes, 2004).
El manantial que presenta una mayor mineralización es el 6, que se ubica en la ribera de laguna Seca, y cuya composición química y relaciones iónicas responden al agua de la laguna principal de Cotacotani. Así, el origen del agua de este manantial correspondería a la descarga del almacenamiento en ribera, de agua de la laguna principal de Cotacotani, cuando el nivel de esta laguna desciende. Las muestras de los manantiales más diluidos muestran valores elevados de la relación $\mathrm{rNa} / \mathrm{rCl}$, que posiblemente están relacionados con un mayor aporte de sodio como consecuencia de la alteración de plagioclasas. Esta hipótesis es coherente con el mayor contenido de sílice que presentan estas aguas.

Las aguas del lago Chungará presentan una composición química muy homogénea, tanto en su distribución de superficie como en profundidad. Son aguas de tipo sulfatado-sódico-bicarbonatado-magnésico, con bajos contenidos de calcio, potasio y cloruro. Los valores de las relaciones iónicas $\mathrm{rNa} / \mathrm{rCl}, \mathrm{rSO}_{4} / \mathrm{rCl}$ y $\mathrm{rMg} / \mathrm{rCl}$ de todas las muestras del lago presentan muy poca variación.

La composición química de las aguas de las lagunas de Cotacotani varía significativamente si estas se encuentran conectadas o no a la laguna principal. Las aguas de la laguna principal de Cotacotani son de tipo sulfatado-magnésico. Los valores de las relaciones iónicas $\mathrm{rNa} / \mathrm{rCl}, \mathrm{rSO}_{4} / \mathrm{rCl}$ y $\mathrm{rMg} / \mathrm{rCl}$ de la laguna principal de Cotacotani y del manantial 6 (correspondiente a la descarga de agua de almacenamiento en ribera de la laguna principal) se aproximan a los valores de estas relaciones obtenidos en el lago Chungará ( $\mathrm{Ta}$ bla 1). Dada la mayor mineralización de las aguas del lago Chungará, sugiere que la laguna principal de 
Cotacotani recibe una aportación significativa de agua del lago Chungará.

Con objeto de verificar si la composición química del agua de la laguna principal de Cotacotani corresponde a mezcla de agua subterránea y de agua procedente del lago Chungará, se ha realizado una modelación hidrogeoquímica aplicando el programa PHREEQC (Parkhurst, 1995). En la simulación de la composición química del agua de la laguna principal se ha mezclado en primer lugar agua de un manantial, con una composición química representativa del agua subterránea, y agua del lago Chungará, a fin de alcanzar las concentraciones de cloruros de las muestras de las lagunas de Cotacotani. Posteriormente se ha puesto en contacto el agua resultante de esta mezcla con algunas fases minerales reconocidas en el medio geológico. Para evaluar los resultados de la solución resultante se ha seguido la evolución del pH,
$\mathrm{pCO}_{2}$ y los índices de saturación de la calcita, la dolomita, el yeso y la magnesita.

La reproducción de la muestra del punto 15 corresponde a una muestra obtenida en el área de laguna Seca, cuando sus aguas forman parte de la laguna principal (noviembre de 2002). La reproducción de esta muestra se obtiene al mezclar $60,5 \%$ de agua del manantial 3 y un $39,5 \%$ de agua del lago Chungará del punto 19. Los resultados de esta mezcla simple reproducen razonablemente bien los contenidos de sodio, sulfato, magnesio y potasio, mientras que los contenidos de carbono y calcio muestran un ligero déficit (Fig. 3). A continuación se ha disuelto 0,31 $\mathrm{mmol} / \mathrm{L}$ de calcita, obteniéndose un mejor ajuste de los contenidos de calcio y carbono. En este sentido, es posible reproducir la composición química de las aguas de la laguna principal de Cotacotani sin considerar efectos de evaporación en la simulación.

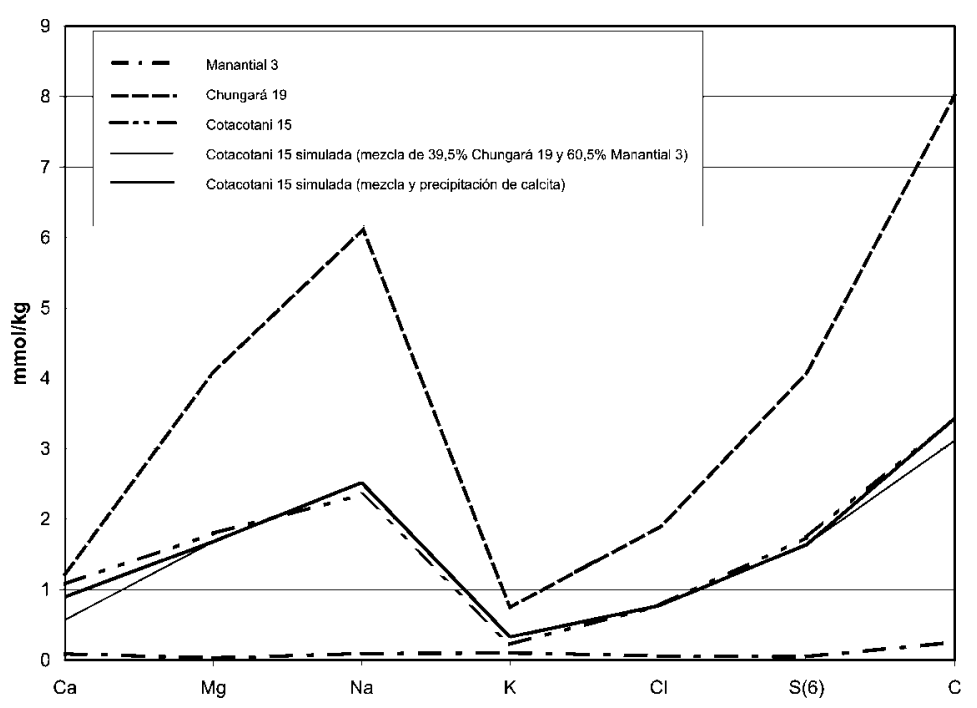

FIG. 3. Representación de las muestras (en $\mathrm{mmol} / \mathrm{kg}$ ) manantial 3, Chungará 19 Cotacotani 15 y de las simulaciones de la composición química de Cotacotani 15.

\section{CARACTERÍSTICAS ISOTÓPICAS DE LA PRECIPITACIÓN}

La caracterización isotópica de la precipitación se ha realizado utilizando datos propios, datos correspondientes a la ciudad de La Paz para el período 1995-1998 [International Atomic Energy Agency (IAEA/World Meterorological Organization $(\mathrm{WMO})]^{1}$ y datos de precipitación correspondien- tes a distintas localidades del norte de Chile (Aravena et al., 1999), de los que sólo se han considerado los correspondientes a localidades situadas a más de 4.000 m s.n.m. Se han utilizado los datos de precipitaciones de la ciudad de La Paz debido a su relativa proximidad al lago Chungará 
(distante $220 \mathrm{~km}$ ) y por la gran cantidad de información existente para los distintos meses del año, lo que permite tener un conocimiento estadístico consistente. Todas las muestras presentan una buena correlación entre $\delta^{18} \mathrm{O}$ y $\delta \mathrm{D}$ en todos los puntos de muestreo, independientemente de la cercanía al área de estudio. Descartadas las muestras sospechosas de enriquecimiento isotópico por evaporación, se ha calculado una línea meteórica local por interpolación lineal mediante mínimos cuadrados: $\delta \mathrm{D}=7,9 \delta^{18} \mathrm{O}+14$ (Fig. 4). $\mathrm{Si}$ se comparan los valores isotópicos de las muestras de precipitación obtenidas en el área de Chungará Cotacotani con los valores isotópicos de las muestras de la ciudad de La Paz, se observa que éstos últimos se ajustan bien a la misma línea meteórica. Esta línea meteórica local varía ligeramente respecto a otras líneas calculadas en sectores próximos: $\delta \mathrm{D}=7,8 \delta^{18} \mathrm{O}$ $+10,3$ para la Pampa del Tamarugal, a partir de datos de precipitación obtenidos en 1973 y 1974 (Fritz et al., 1981); $\delta \mathrm{D}=7,8 \delta^{18} \mathrm{O}+9,7$ para el norte de Chile a partir de datos de precipitación obtenidos en 1983 y 1984 (Aravena et al., 1999); $\delta \mathrm{D}=8,0 \delta^{18} \mathrm{O}+15,2$ para la parte oriental del Altiplano (Gonfiantini et al., 2001).

En el caso de la línea meteórica obtenida por Fritz et al. (1981) en la Pampa del Tamarugal se han considerado muestras de precipitación obtenidas, en la mayoría de los casos bajo los $4.000 \mathrm{~m}$ s.n.m. La línea meteórica obtenida por Aravena et al. (1999) para el norte de Chile también incorpora datos de precipitaciones obtenidas bajo los $4.000 \mathrm{~m}$ s.n.m. Por otro lado, Gonfiantini et al. (2001) obtiene una recta meteórica para la parte oriental del Altiplano más próxima a la obtenida para el área del lago Chungará. Al comparar el valor de exceso de deuterio $(d=\delta D$ $8 \delta^{18} \mathrm{O}$ ) de las muestras de precipitación de la parte oriental del Altiplano y las muestras delárea ChungaráCotacotani se observa una buena correspondencia de los valores. La similitud entre las respectivas líneas meteóricas y la proximidad entre el valor del exceso de deuterio de las precipitaciones en la parte oriental del Altiplano (Gonfiantini et al., 2001), la ciudad de La Paz y los valores obtenidos para las precipitaciones del área Chungará-Cotacotani, hace suponer que las masas de aire que originan las precipitaciones en el área del lago Chungará proceden exclusivamente del Océano Atlántico a través de la cuenca amazónica, de acuerdo con el patrón entendido de la precipitación 'diciembre a marzo'. En este sentido también es posible que los valores más altos de exceso de deuterio de estas precipitaciones reflejen un origen más continental de la masa de humedad atmosférica, como puede ser el agua evaporada en el lago Titicaca y en otros cuerpos de aguas superficiales del Altiplano.

La composición isotópica del agua de lluvia de La Paz se caracteriza por una amplia variación de $\delta^{18} \mathrm{O}$ (entre 1,2 y $-21,1 \%$ ) y de $\delta \mathrm{D}$ (entre 22,5 y $-160,1 \%$ ). Los valores isotópicos más ligeros tendrían su origen en el fuerte fraccionamiento cinético que sufren las masas de aire provenientes de la Amazonía que, al ascender por el margen oriental del Altiplano, se ven afectadas por una disminución progresiva e importante de temperatura. Esto permite una condensación preferencial, la separación del sistema de las moléculas isotópicamente más pesadas $\mathrm{y}$, consecuentemente, un aligeramiento del vapor atmosférico residual. Así, al continuar su desplazamiento hacia el oeste, el vapor atmosférico puede alcanzar una composición isotópica muy ligera.

Los valores de $\delta^{18} \mathrm{O}$ y $\delta \mathrm{D}$ de las precipitaciones de La Paz, Pampa Lirima, Puchuldiza, Collahuasi y del área de estudio, agrupadas según muestras obtenidas en los meses de octubre-marzo y los meses de abril-septiembre, muestran claramente que durante octubre-marzo tienen una composición isotópica más ligera que en los meses más fríos (Figs. 4 y 5). Así, se pueden diferenciar variaciones estacionales en la composición isotópica de las aguas de lluvia. Los valores isotópicos más pesados de las lluvias del período abril-septiembre en La Paz, están relacionados con la menor cantidad de precipitaciones registradas durante ese período, y el consecuente intercambio isotópico con la humedad ambiental si su composición isotópica es diferente. Este fenómeno tiene importancia en lluvias de pequeña intensidad o en los primeros momentos de lluvias intensas y no afecta a la precipitación en forma de nieve (Custodio y Llamas, 1983). La relación entre $\delta^{18} \mathrm{O}$ y precipitación (mm) en las lluvias de la ciudad de La Paz (Fig. 6) muestra como tendencia general que a mayor cantidad de precipitación, la composición isotópica es más ligera. Esta relación entre la cantidad de precipitación y la variación de la composición isotópica también ha sido descrita por Aravena et al. (1999) para las precipitaciones del norte de Chile.

Las muestras obtenidas en este estudio corresponden a precipitación acumulada durante los meses de enero-marzo de año 2002, abril-noviembre de 2002 y enero de 2004 (Tabla 2). Las muestras fueron obtenidas a distintas cotas y estaban localizadas en el poblado de Parinacota (4.380 m s.n.m.), en el refugio de la Corporación Nacional Forestal (CONAF) en el margen sur del lago Chungará (4.590 m s.n.m.) y en 


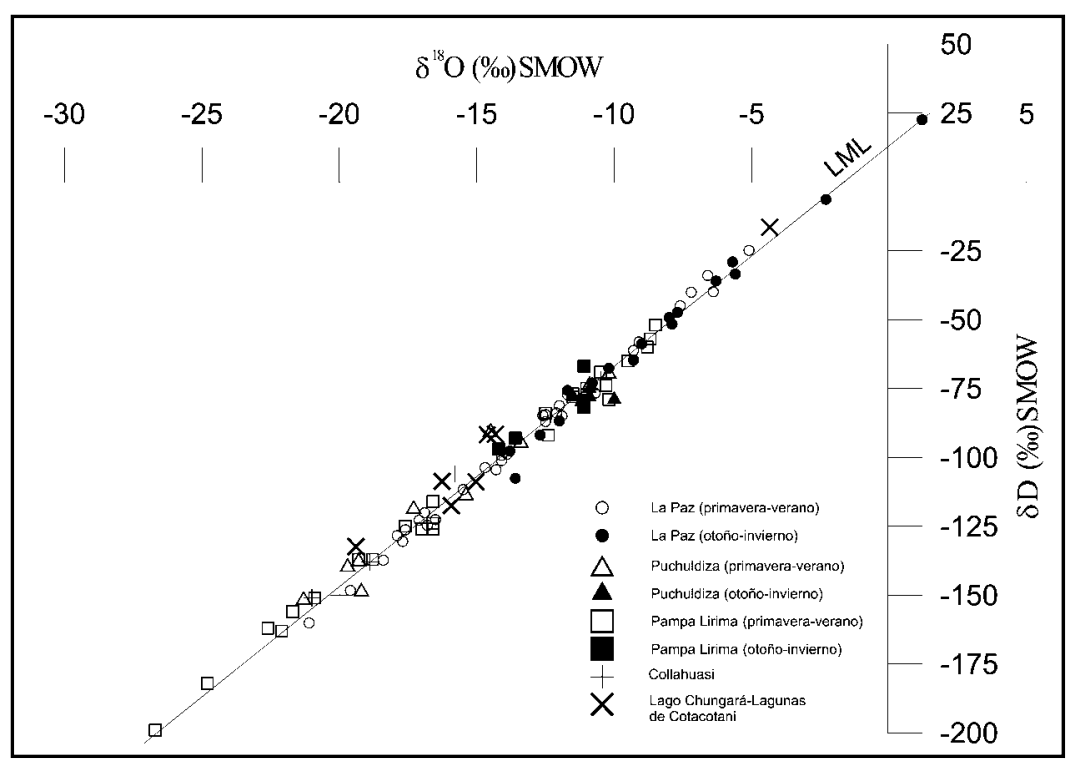

FIG. 4. Composición isotópica $\left(\delta^{18} \mathrm{O}\right.$ y $\left.\delta^{2} \mathrm{D}\right)$ de las muestras de precipitación obtenidas en la ciudad de La Paz por el Organismo Internacional de Energía Atómica (IAEA, 2003) para el período 1995-1998, datos de precipitación obtenidos por Aravena et al. (1999) en distintas localidades del norte de Chile (sólo se han considerado los datos de localidades situadas a más de $4.000 \mathrm{~m}$ s.n.m.) y las muestras obtenidas en esta investigación. LML: Línea meteórica local.

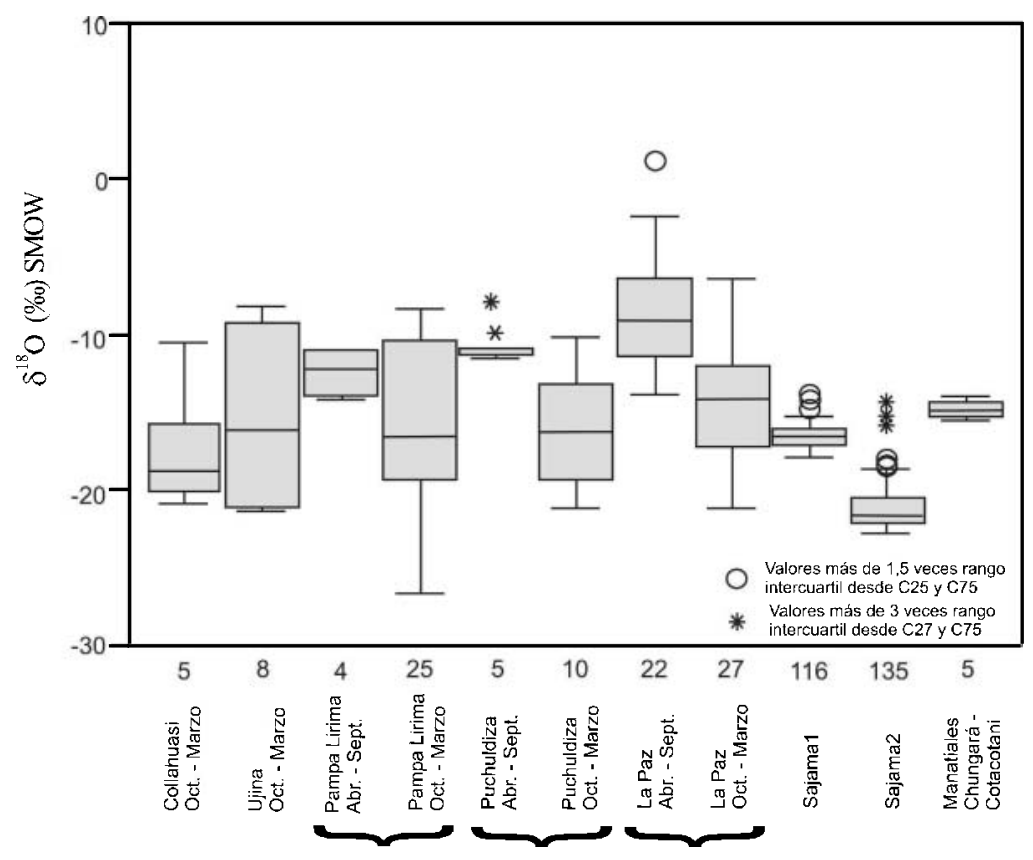

FIG. 5. Diagramas de caja de las muestras de lluvia (diferenciadas según la estación húmeda y seca), nieve (Nevado Sajama) y manantiales del área de estudio. En cada caja achurada está englobado el $50 \%$ de los datos de $\delta^{18} \mathrm{O}$ para cada una de las variables, con el valor mediano representado por la línea horizontal que divide la caja. El límite inferior de la caja corresponde al percentil 25 de la muestra y el límite superior al percentil 75. La línea que se extiende hacia abajo y hacia arriba de cada caja marca el rango de los valores máximos y mínimos comprendidos entre la diferencia del valor de la mediana y 1,5 veces el valor intercuartil (rango comprendido entre los percentiles 75 y 25). Los valores extremos se indican con círculos y asteriscos. Relación entre el valor de $\delta^{18} \mathrm{O}$ y la cantidad de precipitaciones medias mensuales de la ciudad de La Paz (período 1995-1998). 
las cercanías de la cumbre del volcán Ajoya (aproximadamente a 5.000 m s.n.m.). Los datos muestran el efecto altitudinal en la composición isotópica de estas muestras, que se caracteriza por un elevado gradiente isotópico respecto de la altitud. Así, la precipitación acumulada en el verano de 2003 en la estación de Parinacota tiene una $\delta^{18} \mathrm{O}$ de $-4,35 \%$, valor que está muy enriquecido respecto a la muestra de lluvia obtenida para el mismo período en la estación del volcán Ajoya, que tiene una $\delta^{18} \mathrm{O}$ de $-19,4 \%$. Si se considera los valores de $\delta^{18} \mathrm{O}$ de las muestras correspondientes a la estaciones de Parinacota y del volcán Ajoya, se obtiene un gradiente altitudinal de $2,4 \% / 100 \mathrm{~m}$, mientras que si se consideran las muestras de la estaciones del lago Chungará y del volcán Ajoya, el gradiente altitudinal de la $\delta^{18} \mathrm{O}$ se reduce a $0,76 \%$ o/ $100 \mathrm{~m}$. Estos gradientes de composición isotópica obtenidos en el área de estudio son extremadamente altos si se comparan con los existentes en otras regiones del mundo y que, en general, oscilan entorno a 0,25\%/100 m (Plata, 1994). Aravena et al. (1999) también describe elevados gradientes isotópicos respecto de la altitud para las precipitaciones de verano en distintos sectores del norte de Chile que, en el caso del $\delta^{18} \mathrm{O}$, alcanzan $-1 \% / 100 \mathrm{~m}$. Gonfiantini et al. (2001) a partir del muestreo de agua de lluvia mensual también ha determinado gradientes isotópicos respecto de la altitud en el margen oriental del Altiplano que alcanzan los $-0,26 \%$ / $100 \mathrm{~m}$. Aparentemente, el valor del gradiente isotópico altitudinal es más alto si se consideran las muestras de lluvia obtenidas a una altitud más baja, que si se consideran las muestras de gran altitud. Según Gonfiantini et al. (2001) las marcadas diferencias de los gradientes isotópicos con la altitud de la parte oriental y occidental del Altiplano indican el aporte de una segunda fuente de humedad procedente del Océano Pacífico. No obstante, esta hipótesis se contradice con los datos meteorológicos, según los cuales las masas de aire que originan las precipitaciones en el Altiplano del norte de Chile provendrían del Océano Atlántico vía cuenca amazónica (Aravena et al., 1999).

Los valores de la composición isotópica de muestras de granizo del área de las lagunas de Cotacotani coinciden con la composición isotópica de las muestras de lluvia correspondientes a esta misma altitud (ca. 4.500 m s.n.m.) (Fig. 7a). Estos valores indican que el fraccionamiento isotópico de este agua sigue el modelo de Rayleigh para el agua de lluvia con una condensación preferencial, y renovación del sistema, de las moléculas de agua más pesadas. Una explicación para este fenómeno fue dada por Gonfiantini et al. (2001) quien, a partir de una modelación del fraccionamiento isotópico de las precipitaciones en la parte oriental de la Cordillera de los Andes de Bolivia, deduce que el hielo se formó por congelación de gotas de agua de lluvia ya separadas de la fase vapor y que, por tanto, no sufrieron un nuevo fraccionamiento isotópico significativo.

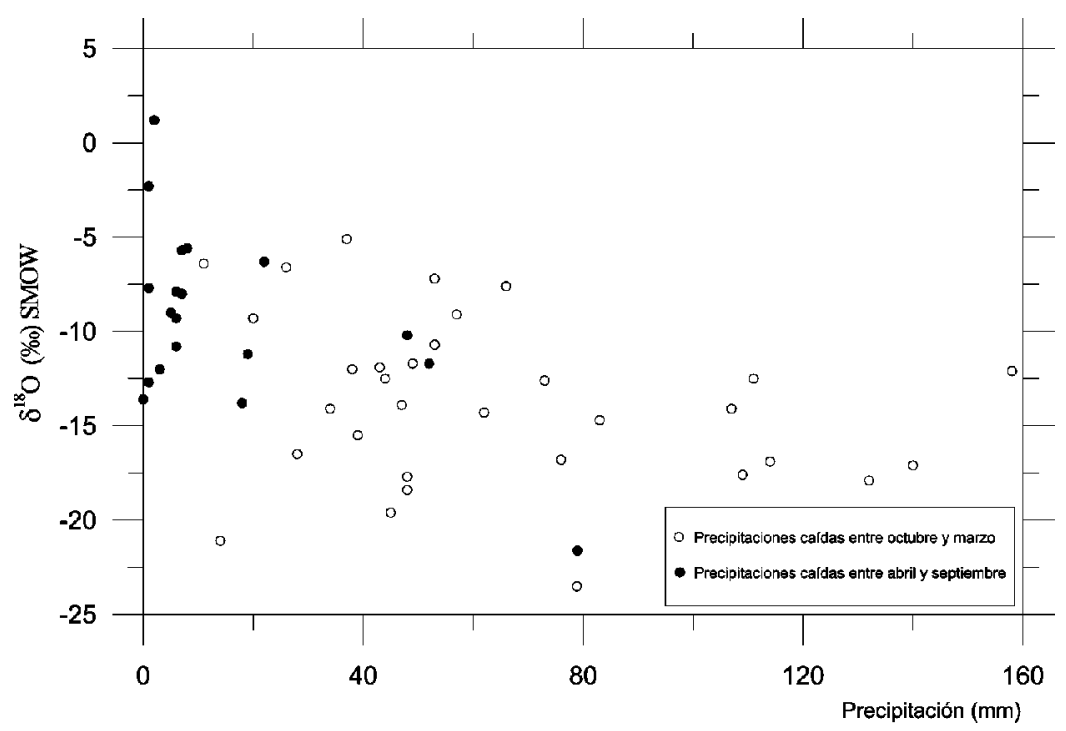

FIG. 6. Relación entre el valor de $\delta^{18} \mathrm{O}$ y la cantidad de precipitaciones medias mensuales de la ciudad de La Paz (período 1995-1998). 


\section{$\delta^{18} O$ Y $\delta D$ DE LAS AGUAS SUPERFICIALES Y SUBTERRÁNEAS}

En la figura 7a se representan todos los datos disponibles de $\delta^{18} O$ y $\delta D$ de las muestras de aguas superficiales y subterráneas del área de estudio, donde se comparan con lalínea meteórica mundial $(\delta \mathrm{D}$ $\left.=8 \delta^{18} \mathrm{O}+10\right)$ y la línea meteórica local $\left(\delta \mathrm{D}=7,9 \delta^{18} \mathrm{O}\right.$ +14) que mejor se ajusta a los datos de precipitación que no han sufrido evaporación. Este gráfico incluye todas las muestras obtenidas en los distintos puntos de muestreo y en distintos períodos, con el fin de evaluarposibles variacionesen lacomposiciónisotópica de las aguas. En general, se observa que las variaciones en la composición isotópica de $\delta^{18} \mathrm{O}$ y $\delta \mathrm{D}$ en las aguas superficiales y subterráneas obtenidas en distintos períodos de tiempo son mínimas y sólo se detectan algunas variaciones significativas en algunas lagunas de Cotacotani, específicamente aquellas lagunas aisladas temporalmente de la laguna principal.

Las aguas del lago Chungará presentan una buena agrupación de los valores de $\delta^{18} \mathrm{O}$ y $\delta \mathrm{D}$ y están considerablemente enriquecidas respecto a las aguas de los manantiales (Fig. 7a). El valor medio de la $\delta^{18} \mathrm{O}$ es de $-1,4 \%$ y el de $\delta D$, de $-43,4 \%$. Las aguas del lago se caracterizan por presentar una composición isotópica muy homogénea en la vertical, indicando una buena mezcla de las aguas del lago, al menos durante el período de muestreo. Sólo las muestras obtenidas a más de $20 \mathrm{~m}$ de profundidad, muestran una composición de $\delta^{18} \mathrm{O}$ y $\delta \mathrm{D}$ algo más ligeras respecto que las muestras obtenidas a menor profundidad (Tabla 3). No obstante, estas diferencias no superan el $4 \%$ ॰ para la $\delta \mathrm{D}$, y el $0,2 \%$ o para la $\delta^{18} \mathrm{O}$, diferencias que son próximas al error analítico.

Las composiciones isotópicas de $\delta^{18} \mathrm{O}$ y $\delta \mathrm{D}$ en las aguas subterráneas, caracterizadas a partir del agua de los manantiales, presentan una composición isotópica muy ligera, con un valor medio de $\delta^{18} \mathrm{O}$ de $-15,8 \%$ y un valor de $\delta D$ de $-115 \%$. Estos valores responden a la composición isotópica de las precipitaciones más ligeras que ocurren en los meses de verano (Fig. 7a). Todas las muestras se sitúan muy próximas entre sí y sobre la línea meteórica local, o ligeramente por debajo de la misma. Esto indica en algunos casos la posibilidad de un moderado efecto de evaporación durante la infiltración del agua de lluvia. Las bajas temperaturas que se registran en el área durante todo el año no favorecen una evaporación importante a pesar de la escasa cobertura vegetal.
Esto es coherente con los bajos valores estimados de evaporación media mensual potencial durante los meses de verano de apenas 135 mm (DGA, 1987). En aquellas muestras de manantiales que no presentan efectos de evaporación, el valor de exceso de deuterio (d) de las aguas varía entre $+14 \% \circ y+19 \%$, siendo estos valores iguales o ligeramente inferiores a los valores de exceso de deuterio reconocidos en las precipitaciones (Tablas 2 y 3 ). Esto muestra el origen más continental de las masas de humedad que originan la recarga de los acuíferos.

La composición isotópica del agua del río Chungará es similar a la de las aguas de los manantiales (Fig. 7a). Esto es afín con el hecho de que las aguas que dan origen a este río son esencialmente aguas subterráneas que afloran en los distintos bofedales del sector. Al comparar los valores de exceso de deuterio de las aguas del río Chungara con las aguas de los manantiales se observa una buena correspondencia de valores y demuestra la ausencia de efectos de evaporación en las aguas del Río, a pesar de que las muestras fueron tomadas en verano y en el curso final del río, poco antes de desembocar en el lago Chungará (Tabla 3).

Las aguas de las lagunas de Cotacotani presentan unas composiciones de $\delta^{18} \mathrm{O}$ y $\delta \mathrm{D}$ variables según estén conectadas, temporal o permanentemente, a la laguna principal. Así, las aguas de la laguna principal tienen una composición isotópica constante en el tiempo, caracterizada por presentar valores intermedios entre la composición isotópica de las aguas del lago Chungaráy las aguas subterráneas muestreadas a partir de los distintos manantiales (Fig. 7a). La composición isotópica de las muestras de la laguna principal de Cotacotani, tienen valores medios de $\delta^{18} \mathrm{O}$ de $-7,5 \%$ y de $\delta \mathrm{D}$ de $-75,1 \%$. Del mismo modo que la composición isotópica de $\delta^{18} \mathrm{O}$ y $\delta$ D de la laguna principal, las concentraciones de cloruro de estas aguas son aproximadamente intermedias entre las concentraciones de las aguas de los manantiales y las aguas del lago Chungará (Fig. 7b). Por otro lado, las lagunas de Cotacotani presentan valores de exceso de deuterio (d) negativos que permiten deducir efectos de evaporación. No obstante, en el caso de la laguna principal de Cotacotani y otras lagunas, los valores de exceso de deuterio no son determinantes para definir si las aguas han sido afectadas por evapo- 

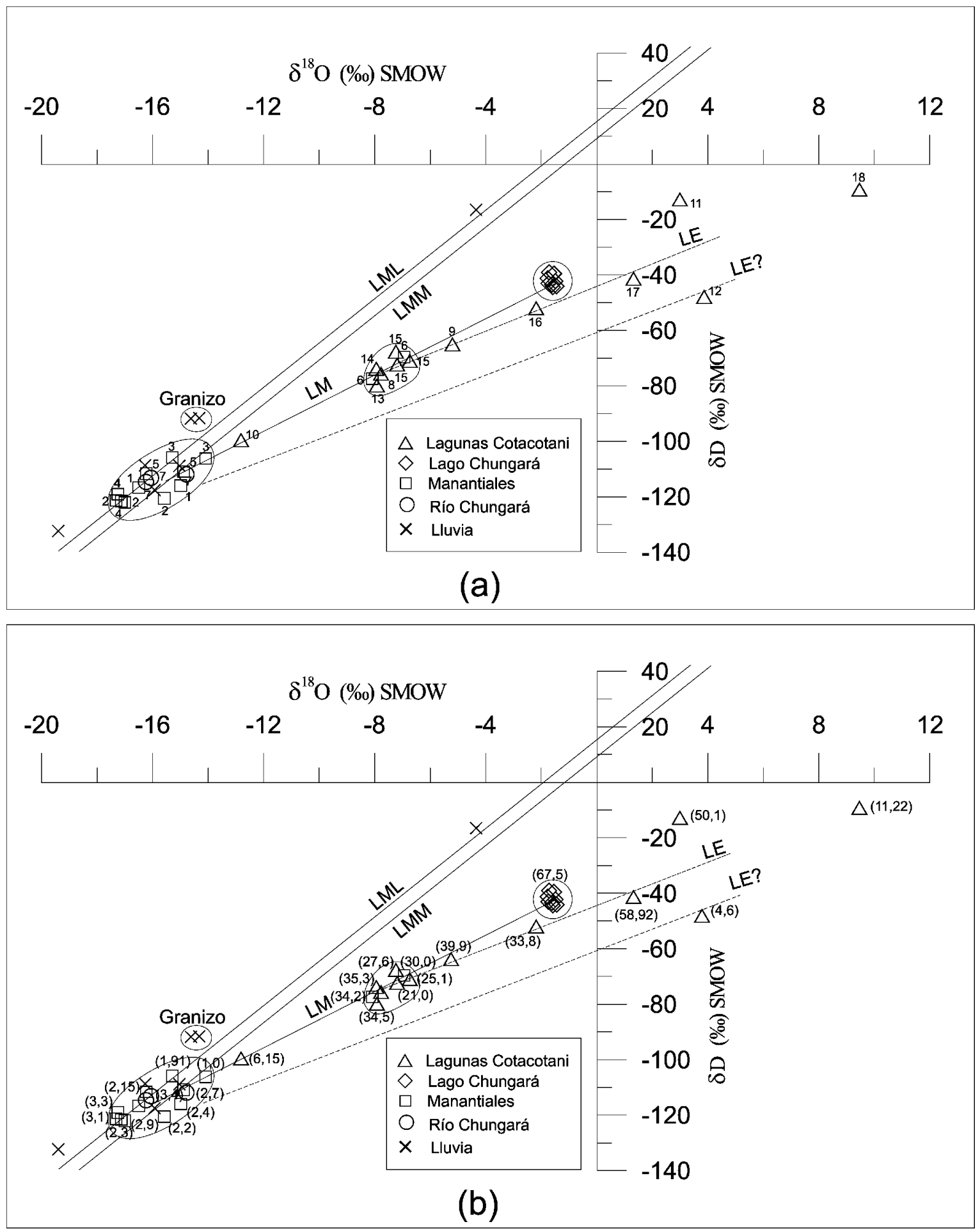

FIG. 7. a. Composición isotópica $\left(\delta^{18} \mathrm{O} / \delta \mathrm{D}\right)$ correspondiente a la precipitación, lagunas de Cotacotani, lago Chungará y manantiales del área de estudio. LMM: Línea meteórica mundial; LML: Línea meteórica local; LM: Línea de mezcla; LE: Línea de evaporación; $b$. Composición isotópica $\left(\delta^{18} \mathrm{O} / \delta \mathrm{D}\right)$ y concentración de cloruro (entre paréntesis) de las lagunas de Cotacotani, lago Chungará y manantiales. 
ración, debido a que corresponden a la mezcla de agua subterránea y agua del lago Chungará que ya tiene efectos de evaporación.

La mayoría de las muestras de agua correspondientes a lagunas que tienen una conexión intermitente con el sistema de la laguna principal, muestran composiciones isotópicas de $\delta^{18} \mathrm{O}$ y $\delta \mathrm{D}$ con un claro fraccionamiento por evaporación (muestras 16 y 17 ; Fig. 1). También presentan mayores contenidos en cloruro respecto a las aguas de la laguna principal de Cotacotani (Fig. 7b). Estas muestras se proyectan alineadas según una pendiente de evaporación de 4,1 (Fig. 7a) que resulta ser la correspondiente a evaporación a partir de agua libre, con una humedad relativa entre 25 y $50 \%$ (Gonfiantini, 1986). Por otro lado, las aguas de las lagunas que están permanentemente aisladas de la laguna principal pueden tener composiciones isotópicas muy variables, dependiendo del grado de mezcla de aguas del lago Chungará con aguas subterráneas y mostrando, generalmente, importantes fraccionamientos por evaporación.

Algunas muestras de las lagunas de Cotacotani más próximas al lago Chungará, como es el caso de los puntos 9, 10, 11 y 12 (Fig. 1), presentan composiciones isotópicas $\delta^{18} \mathrm{O}$ y $\delta \mathrm{D}$ que se alejan de la agrupación de puntos anteriormente descrita (Figs. 7a y 7 b, Tabla 3). La muestra del punto 9 corresponde a una laguna aislada situada en los depósitos volcánicos de brecha. Su composición isotópica más enriquecida y su mayor concentración de cloruro respecto a la agrupación de puntos de la laguna principal de Cotacotani, indican un fraccionamiento isotópico por evaporación. La muestra obtenida en el punto 10 corresponde a una laguna aislada, situada al sur del resto de lagunas, cerca del lago Chungará, y se caracteriza por presentar composiciones isotópicas más ligeras, que la sitúan en la línea de mezcla de las aguas de los manantiales y del lago, pero muy próxima a la composición isotópica del agua de los manantiales (Tabla 3). Esta muestra tiene una composición isotópica y un contenido en cloruro que indica un mayor aporte de agua subterránea respecto a la contribución de agua del lago Chungará. El punto 11 corresponde a una pequeña laguna, de escasa profundidad $(0,5$ $\mathrm{m})$, situada a $80 \mathrm{~m}$ del lago Chungará que, muy probablemente, está alimentada por agua del mismo, en períodos en que el nivel del lago sube, y por las precipitaciones que caen directamente sobre la misma. La composición isotópica más próxima a la línea meteórica local y la menor concentración de cloruro respecto al agua del lago Chungará, hace suponer un aporte importante de agua de lluvia a esta laguna. Por esa razón, la evaporación que posteriormente ocurre en la laguna, la obliga a seguir una línea evolutiva que partiría de una composición isotópica distinta al agua del lago Chungará. El punto 12 corresponde al agua de una pequeña laguna formada por la descarga de un manantial en el frente de la colada de 'Lava de Ajata', siendo su composición isotópica más pesada y su contenido en cloruro mayor respecto al agua de los manantiales (Fig. 7b). Las composiciones isotópicas del agua en esta laguna muestran los efectos de la evaporación, sobre el agua subterránea, de los acuíferos de los flancos de los volcanes (representados por los manantiales) sin sufrir mezcla con el agua procedente del lago Chungará.

El punto 18 corresponde a una pequeña laguna de poca profundidad $(0,2 \mathrm{~m})$ ubicada en la parte sur del sistema de lagunas. Por su mayor altitud, esta laguna permanece desconectada permanentemente de la laguna principal de Cotacotani. El mayor enriquecimiento isotópico que presenta, así como su menor concentración en cloruros, hace suponer que la laguna contiene, esencialmente, agua de los acuíferos situados en los flancos de los volcanes que incorporan en parte agua de las precipitaciones que caen directamente en la laguna. Esto también es coherente con la composición química y relaciones iónicas de esta agua, que la sitúan más próxima a la composición química de las aguas de los manantiales que a las lagunas de Cotacotani, aunque muestra evidentes efectos de concentración por evaporación.

Utilizando los valores medios de $\delta^{18} \mathrm{O}$ de las lagunas de Cotacotani, y una vez descartadas las muestras sospechosas de haber sido afectadas por evaporación, se ha efectuado un balance de masas con objeto de evaluar la contribución a las mismas, de aguas del lago Chungará y de aguas subterráneas. Se asigna valor 1 a las aguas de las lagunas de Cotacotani, valor $X$ a la contribución de las aguas subterráneas, y valor $1-X$ a la contribución del lago Chungará. La contribución de estos tipos de agua a las lagunas de Cotacotani será:

$$
X(-15,8)+(1-X)(-1,4)=1(-7,5)
$$

El resultado de este balance indica que las aguas de las lagunas no aisladas de Cotacotani están constituidas aproximadamente por un $42 \%$ de agua subte- 
rránea de los acuíferos que flanquean los volcanes y por un $58 \%$ de aguas procedentes del lago Chungará en el acuífero del depósito volcánico de brechas. Estos valores son muy cercanos a los resultados obtenidos con la modelación hidrogeoquímica presentada anteriormente. Si se considera que la laguna principal de Cotacotani descarga sus aguas en el río Desaguadero, con un caudal medio de $0,44 \mathrm{~m}^{3} \mathrm{~s}^{-1}$ (DGA, 1987), y se desprecian las pérdidas por evaporación (dado que existe un flujo continuo de agua en la laguna principal), se obtiene que la descarga subterránea del lago Chungará hacia las lagunas es de aproximadamente $0,25 \mathrm{~m}^{3} \mathrm{~s}^{-1}$.

El hecho de que aproximadamente el $58 \%$ del agua de las lagunas de Cotacotani provenga del lago Chungará demuestra la existencia de un importante flujo de agua subterránea a través de los depósitos de brechas volcánicas, desde el lago Chungará hacia las lagunas. Si bien no existen pozos que permitan definir las características de este flujo subterráneo, se ha estimado el gradiente piezométrico medio de las aguas subterráneas considerando el desnivel existente entre ambos cuerpos de aguas superficiales y la distancia horizontal que los separa. Así se obtiene un bajo gradiente hidráulico de sólo 0,004, que indicaría una alta permeabilidad de los depósitos de brechas que separan a ambas subcuencas.

Se ha demostrado la existencia de flujos de agua subterráneos entre cuencas cerradas, en terrenos volcánicos en otras cuencas del Altiplano del norte de Chile. Es el caso de las cuencas de los Salares de Michincha y de Coposa, situadas $200 \mathrm{~km}$ al sur del lago Chungará; entre ellas se ha calculado un flujo subterráneo de $0,2 \mathrm{~m}^{3} \mathrm{~s}^{-1}$ a partir de un estudio estratigráfico y piezométrico detallado (Montgomery et al., 2003).

La comparación mediante diagramas de cajas de los valores de $\delta^{18} \mathrm{O}$ de todas las muestras de agua de manantiales obtenidas en Chungará-Cotacotani con los valores isotópicos de la precipitación (Aravena et al., 1999) y los valores isotópicos de la nieve de Nevado Sajama (Thompson, 2000) muestran las marcadas diferencias de los valores medianos de $\delta^{18} \mathrm{O}$ de la lluvia correspondiente a los meses de primavera-verano (octubre-marzo) con los meses de otoño-invierno (abril-septiembre; Fig. 5). Los valores isotópicos de las precipitaciones de primavera-verano, que en general se ajustan a un valor de $\delta^{18} \mathrm{O}$ de $-16 \%$, se aproximan más al valor mediano de $\delta^{18} \mathrm{O}$ de las aguas de los manantiales respecto a las muestras de lluvia de otoño-invierno. Si se tiene en cuenta la mayor cantidad de muestras lluvia correspondientes a la ciudad de La Paz para la primavera-verano, se observa que la correspondencia con el valor mediano de $\delta^{18} \mathrm{O}$ de los manantiales es aún más clara. Esto permite afirmar que la recarga del agua que da origen a los manantiales del área de Chungará-Cotacotani se produce casi exclusivamente como consecuencia de las lluvias ocurridas en los meses de primavera-verano.

EI Nevado Sajama se localiza $40 \mathrm{~km}$ al noreste del área de estudio y alcanza una altitud de $6.540 \mathrm{~m}$ s.n.m. Sus muestras corresponden a un sondeo en hielo de $150 \mathrm{~m}$ de profundidad, realizado en el glaciar y en el que se han diferenciado dos unidades (Thompson et al., 2000): a. Las muestras de la unidad superior, que corresponden a los últimos 12.000 años, tienen una composición isotópica muy estable, en torno a un valor de $\delta^{18} \mathrm{O}$ de $-17,2 \%$, y b. Las muestras de la unidad inferior, con una edad entre 12.000 y 20.000 años, se caracterizan por presentar una $\delta^{18} \mathrm{O}$ media de $-21,5 \%$. Las composiciones isotópicas de las muestras de agua subterránea de los manantiales de Chungará-Cotacotani se corresponden bien con la composición isotópica de la nieve que ha caído durante los últimos 12.000 años, por lo que inicialmente se puede afirmar que estas aguas han sido recargadas con posterioridad al último período de glaciación.

\section{EDADES DE LAS AGUAS DE LOS MANANTIALES}

La edad de las aguas que dan origen a los distintos manantiales del área del lago Chungará se ha determinado a partir del análisis de su contenido en tritio. El tritio es un isótopo radioactivo del hidrógeno $\left({ }^{3} \mathrm{H}\right)$ que decae ${ }^{3}{ }^{3} \mathrm{He}$ por emisión de partículas beta, y tiene un período de semidesintegración de 12,33 años
(Takaoka y Mizutani, 1987). El tritio producido en la atmósfera, ya sea de forma natural o artificial, pasa a formar parte de las moléculas de agua y se incorpora al ciclo hidrológico, donde se comporta como un trazador. Las explosiones termonucleares realizadas en los años sesenta inyectaron en la atmósfera grandes can- 
tidades de tritio, que sobrepasaron con creces las concentraciones naturales. De este modo se generó una importante anomalía de tritio a nivel mundial en las precipitaciones registradas en los años 1963-1964, que en la estación de Ontario (Canadá) alcanzaron un máximo de 10.000 U.T. Dicha anomalía fue mucho menor en América del Sur, alcanzando un valor máximo de 290 U.T. en Río de Janeiro.

La distribución de los contenidos de tritio en las precipitaciones, durante los períodos en que se produce la recarga, puede ser utilizada como función de entrada del trazador. Como se deduce del estudio de las composiciones isotópicas $\left(\delta^{18} \mathrm{O}\right.$ y $\delta \mathrm{D}$ ) en ChungaráCotacotani, la recarga al sistema acuífero se produce principalmente por las precipitaciones correspondientes a los meses de primavera y verano. Por tanto, la función de entrada de los valores de tritio ha sido ponderada respecto al valor medio mensual de la precipitación.

Una de las dificultades para la construcción de la función de entrada de tritio en el área de estudio es la falta de un control continuo de la actividad de tritio en el agua de lluvia desde 1954 hasta la actualidad. En Sudamérica no existe ninguna estación de observación con una serie continua de datos, siendo las más completas las del Organismo Internacional de Enegía Atómica (OIEA) situadas en Porto Alegre y Río de Janeiro. Hay cuatro estaciones de observación a una latitud relativamente próxima al área de Chungará-Cotacotani, cuyos datos han permitido completar de manera aproximada la función de entrada de tritio: Cuzco (3.246 m s.n.m.) en Perú, La Paz (4.071 m s.n.m.) en Bolivia, y Los Molinos (1.300 m s.n.m.) y Salta (1.187 m s.n.m.) en Argentina. No obstante, para poder interpretar correctamente los resultados de tritio es preciso conocer sus concentraciones en el agua de lluvia desde 1953, cuando se iniciaron los ensayos termonucleares en la atmósfera. Por esta razón, para el período comprendido entre 1954 y 1968 la serie fue completada con datos de tritio de Puerto Alegre y Río de Janeiro, en Brasil. Los contenidos en tritio del agua de lluvia de cada una de las estaciones indicadas anteriormente ponen de manifiesto la anomalía mundial de tritio de mediados de los años sesenta (Fig. 8). Dichos contenidos evolucionan de forma similar para las distintas estaciones consideradas, lo que permite utilizar los contenidos en tritio de cada una de ellas como referentes de una función de entrada del contenido del agua de lluvia.

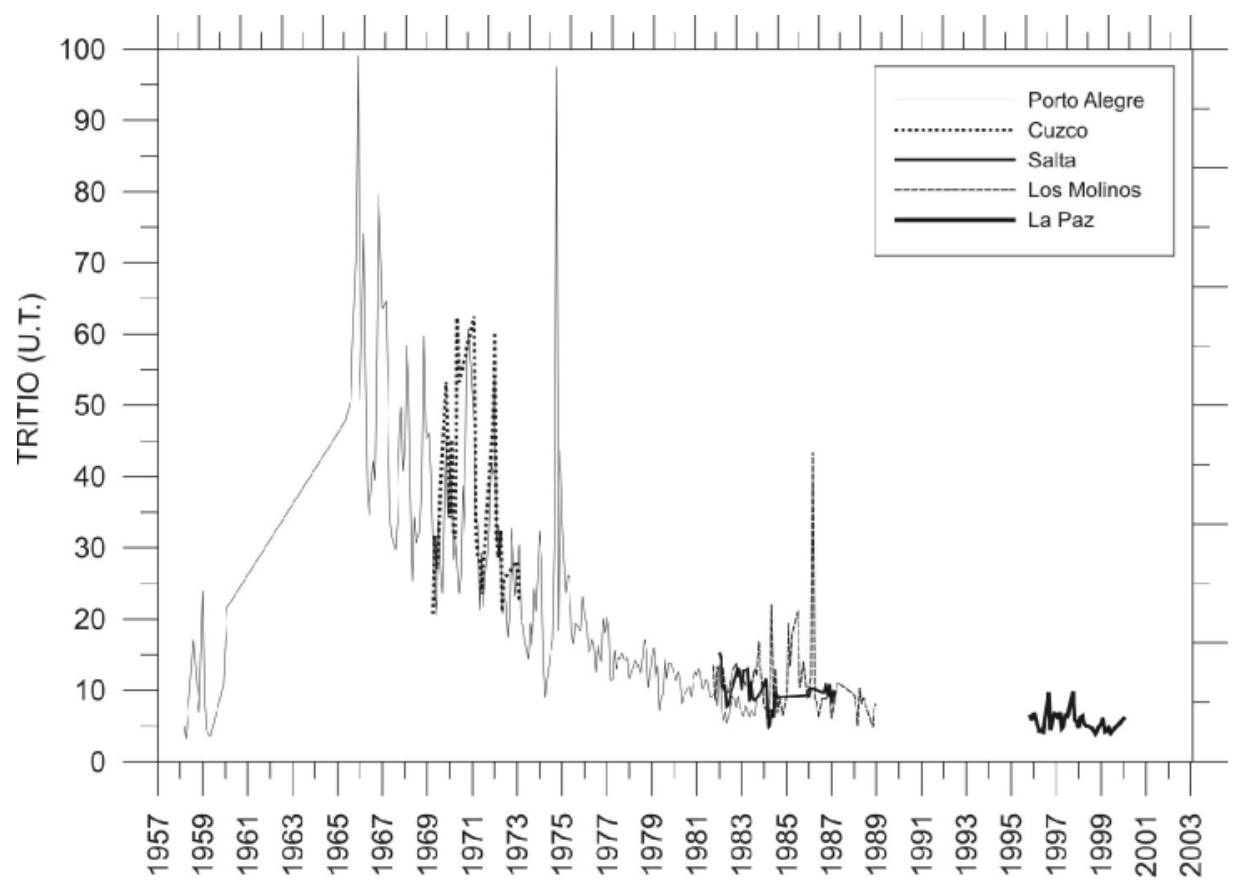

FIG. 8. Concentración de tritio mensual del agua de lluvia medido en las estaciones del Organismo Internacional de Energía Atómica de Porto Alegre (Brasil), Cuzco (Perú), Salta (Argentina), Los Molinos (Argentina) y La Paz (Bolivia). 
Los datos de la estación de Los Molinos muestran una anomalía en el año 1986, con un aumento en el contenido de tritio de 43,4 U.T. (Fig. 8), que no se observa en otras estaciones de la región, lo que hace suponer su carácter local. Dado que la estación de Los Molinos se ubica aproximadamente $1.000 \mathrm{~km}$ al sur del área de estudio, es difícil que los efectos de esta anomalía hayan afectado las precipitaciones en el área estudiada. No obstante, considerando esa posibilidad, se ha trabajado con dos funciones de entrada: la función 1 , que no considera la anomalía de tritio de Los Molinos (Fig. 9), y la función 2, que si la considera (Fig. 10). En ambos casos, los contenidos de tritio anuales han sido ponderados respecto al valor medio mensual de las precipitaciones que se registran en la localidad de Parinacota, según:

$$
\mathrm{Tp}_{\mathrm{j}}=\frac{\sum \mathrm{T}_{\mathrm{i}} \mathrm{P}_{\mathrm{i}}}{\sum \mathrm{P}_{\mathrm{i}}}
$$

$\mathrm{Tp}_{\mathrm{j}}=$ contenido medio de $\mathrm{T}$ (en U.T.) de la lluvia del año $\mathrm{j}$

$\mathrm{T}_{\mathrm{i}}=$ contenido de $\mathrm{T}$ en la lluvia del mes $\mathrm{i}$ (U.T.)

$\mathrm{P}_{\mathrm{i}}=$ precipitación del mes $\mathrm{i}(\mathrm{mm})$

Los contenidos en tritio de las aguas de los manantiales, medido en el sector ChungaráCotacotani, muestran variaciones según su localización (Tabla 3), pudiéndose diferenciar tres grupos de manantiales: a. los situados al norte del volcán Ajoya, con contenidos de tritio entre 1,5 y 2,5 U.T.; b. el manantial 1 y el río Chungará, situados al este del volcán Ajoya, con contenidos de tritio en torno a la 5 U.T., y c. el manantial 5 situado al frente de una colada de lava del volcán Parinacota y que tiene una concentración de tritio de 8 U.T.

La interpretación de los datos de tritio se ha realizado mediante modelos de parámetros agregados con la aplicación del código MULTIS (Ritchter et al., 1992). Generalmente estos modelos ignoran variaciones espaciales y suponen que todo el acuífero se comporta homogéneamente. El principal parámetro de estos modelos es el tiempo medio de residencia o de renovación, que corresponde al cociente entre el volumen de agua circulante y el caudal medio anual drenado por el sistema en régimen estacionario (Lambán, 1998). Para aplicarlos y conocer el tiempo de residencia de las aguas subterráneas es preciso establecer un modelo teórico de funcionamiento del sistema. Una condición ideal para la aplicación de los modelos agregados se consigue con una observación prolongada en el tiempo de los contenidos de tritio en cada uno de los puntos muestreados. Esta condición permitiría evaluar la tendencia general de decaimiento del contenido de tritio en cada uno de ellos y, por lo tanto, conocer cuál de los modelos agregados es el que mejor se ajusta al sistema acuífero en cuestión. No obstante, una aplicación inicial de estos modelos, aunque no sea en las condiciones ideales mencionadas, permite obtener una primera aproximación del tiempo de residencia del agua en el acuífero.

Los modelos básicos corresponden al modelo de flujo de pistón y el modelo exponencial(Malozewski y Zuber, 1982). El modelo de flujo de pistón supone un medio homogéneo en que todas las líneas de flujo tienen la misma velocidad y tanto la dispersión hidrodinámica como la difusión molecular son despreciables, de manera que el tritio se mueve desde la superficie con la velocidad media del agua. En este modelo no se produce ningún tipo de mezcla y las aguas más jóvenes van desplazando a las de edades mayores (Iglesias, 1999). El modelo exponencial supone una mezcla total de los diferentes componentes delárea de recarga, desde los más recientes a los más antiguos. El sistema acuífero se considera como un almacén donde se produce la mezcla, aunque físicamente no sucede así, sino que la mezcla se produce en la zona de descarga (pozos o manantiales), donde convergen distintas líneas de flujo con distintos tiempos de circulación en el acuífero.

La aplicación del problema directo con el modelo de flujo de pistón para la función 1 de entrada que no considera la anomalía de tritio de Los Molinos, con las funciones de salida obtenidas para tiempos de permanencia de 10, 20 y 35 años (Fig. 9), muestran que el mejor ajuste para el agua del manantial 5 corresponde a un tiempo de residencia de aproximadamente 35 años (la mayor anomalía a nivel mundial del año 1964). La función 2 de entrada, que considera la anomalía de tritio de Los Molinos, con las funciones de salida obtenidas al aplicar el modelo de flujo de pistón para tiempos de permanencia de 10,15, 20, 35 y 40 años (Fig. 10), muestran dos posibilidades de ajuste para el contenido de tritio medido en la muestra del manantial 5: 15 y 35 años de tiempo de residencia. En ambos casos los contenidos en tritio de la función de salida que mejor se ajustan al contenido de tritio medido en el manantial, son la anomalía mayor del año 1964 y la anomalía de 1986 de Los Molinos. Como 


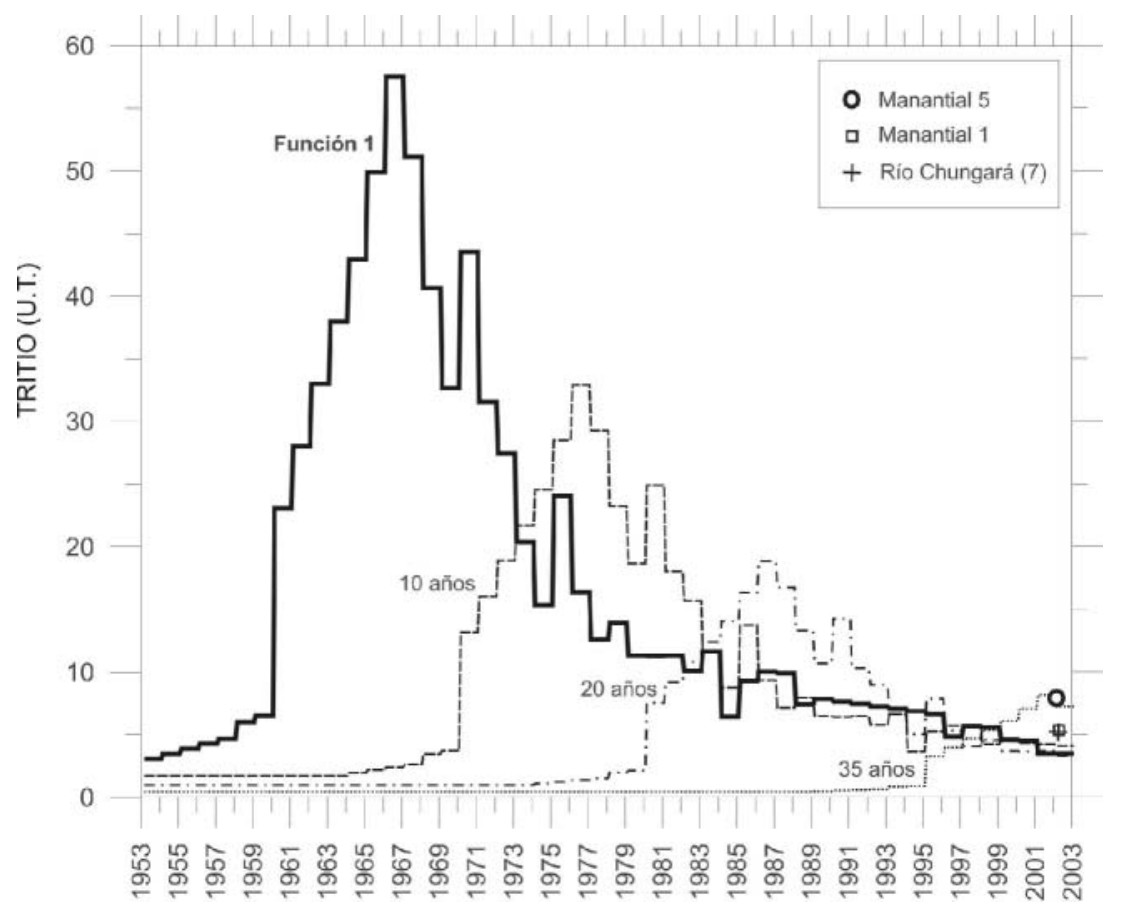

FIG. 9. Función de entrada 1 y funciones de salida a partir de la aplicación del modelo de flujo de pistón para tiempos de permanencia de 10,20 y 35 años.

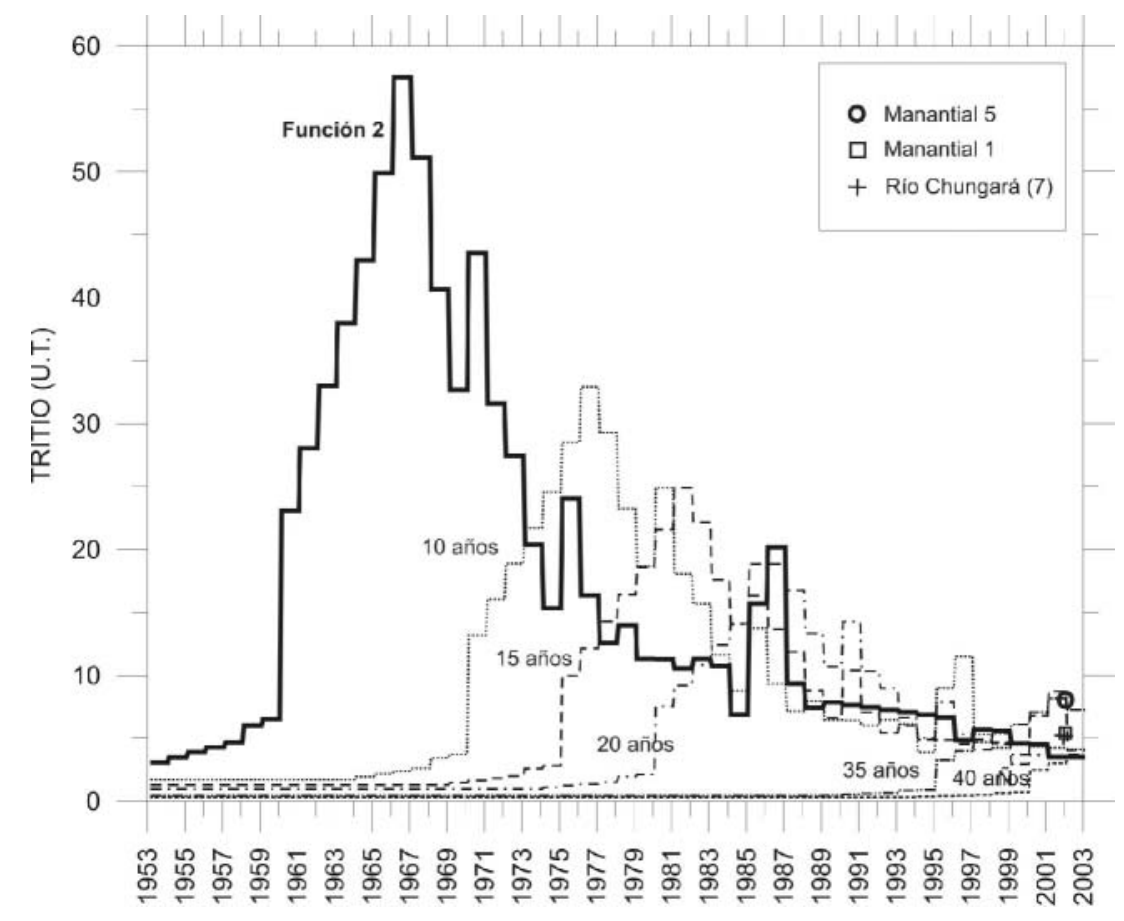

FIG. 10. Función de entrada 2 y funciones de salida a partir de la aplicación del modelo de flujo de pistón para tiempos de permanencia de $10,15,20,35$ y 40 años. 
se indicó anteriormente, esta anomalía no se reconoce en otras estaciones de control del Organismo Internacional de Energía Atómica en la región, por lo que es posible que corresponda a un valor anómalo local. Así, el tiempo de permanencia más probable al aplicar el modelo de flujo de pistón es de 35 años.

Los contenidos de tritio medidos en el manantial 1 y en el agua del río Chungará (Figs. 9 y 10) también muestran una aproximación relativamente buena con algunas de las funciones de salida obtenidas al aplicar el modelo de flujo de pistón. En ambos casos las muestras presentan un contenido de tritio algo mayor respecto a las funciones de salida con tiempos de residencia de 10 y 20 años. No obstante, si se consideran las incertidumbres de estas determinaciones $( \pm \sigma)$, se puede asumir en este caso la validez del modelo. Por otro lado, la mayor concentración de tritio medida en el río Chungará (5,1 U.T.) hace suponer que las aguas que dan origen al mismo corresponden a la descarga de agua de manantiales de pequeños acuíferos colgados.
A partir de la resolución del problema directo con el modelo exponencial, considerando la aplicación de la función 2 de entrada, las distintas funciones de salida para tiempos de permanencia de 10,25, 50 y 100 años (Fig. 11) indican la poca influencia de la anomalía de tritio de 1986 de la estación de Los Molinos. Estos resultados muestran que se logra un buen ajuste entre los 50 y 100 años de tiempo de residencia para los manantiales situados en la parte norte del volcán Ajoya y cuya concentración de tritio varía entre 1,5 y 2,5 U.T. Estos valores sugieren que las aguas que afloran en esos manantiales obedecen a una mezcla de aguas recargadas con anterioridad a la anomalía de tritio de 1964 y aguas recargadas con posterioridad a ese evento. Por otro lado, la aplicación del modelo exponencial no resulta factible para evaluar el tiempo de residencia de las aguas del manantial 5 , debido a que todos los tiempos de residencia obtenidos al aplicar tanto la función de entrada 1 como la 2, son muy inferiores a la concentración de tritio medida en este manantial.

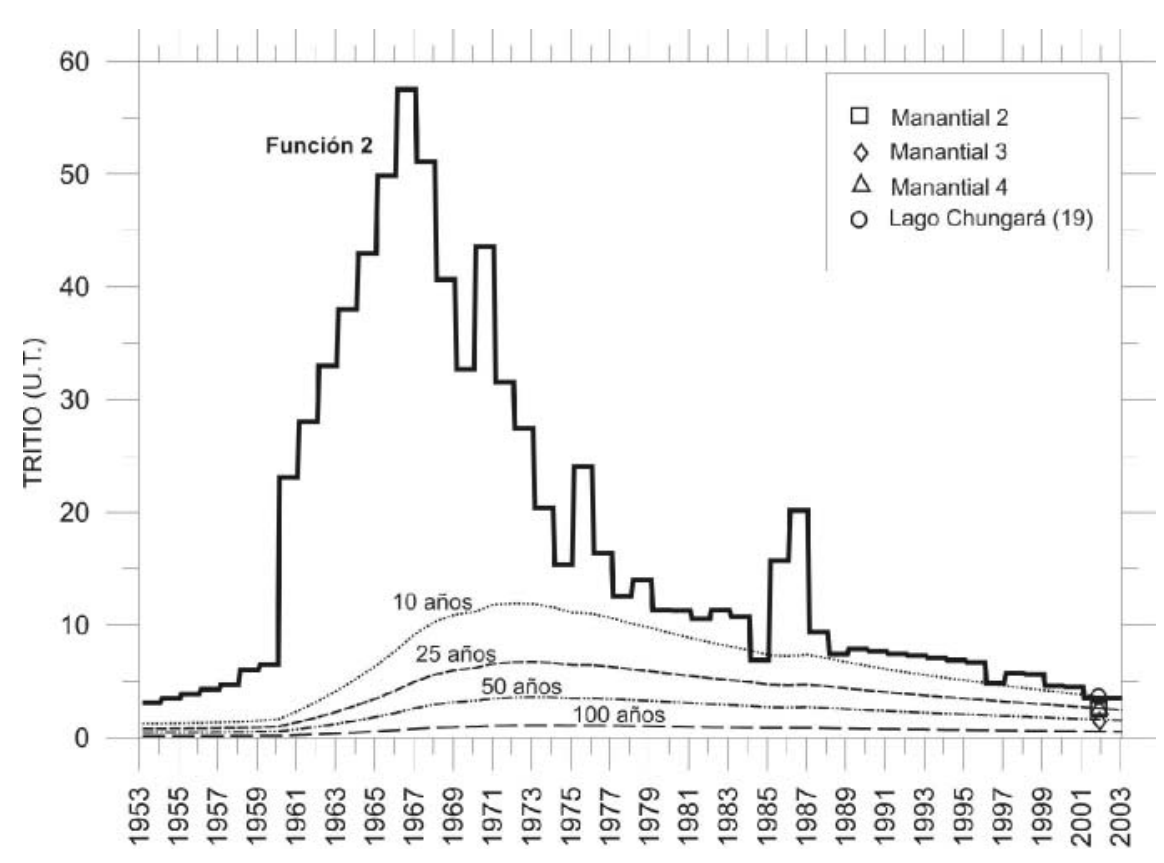

FIG. 11. Función de entrada 2 y funciones de salida a partir de la aplicación del modelo exponencial para tiempos de permanencia de 10, 25,50 y 100 años.

A diferencia del manantial situado en el frente de la colada de 'Lava de Ajata', los manantiales reconocidos al norte del volcán Ajoya (manantiales 2, 3 y 4) surgen a una altitud similar, coincidiendo con las partes más bajas de los barrancos excavados por antiguos glaciares. Esta situación posiblemente indica que su 
origen se debe a la intersección del nivel de saturación regional con la topografía y, por tanto, el agua que mana de los mismos corresponde a una mezcla de aguas recargadas a distintas cotas y en distintos materiales volcánicos, que a su vez dan lugar a una mezcla de distintos tiempos de residencia de agua en el acuífero (Fig. 12). En este contexto, los resultados obtenidos con la aplicación del modelo exponencial, o de mezcla total, se ajustan razonablemente bien a las concentraciones de tritio medidas en estos manantiales. Las aguas que surgen de manantiales situados en la parte oriental del volcán Ajoya y que dan origen al río Chungará (manantial 1) muestran contenidos en tritio más altos, que no pueden ser explicados por el modelo exponencial (Tabla 3). En este sentido, el modelo de flujo de pistón es el único que se ajusta bien a los contenidos de tritio medidos. La aplicación de este último modelo al caso que nos ocupa hace suponer que los manantiales corresponden a la descarga de acuíferos colgados con un funcionamiento similar al indicado para el caso del manantial 5 del volcán Parinacota.

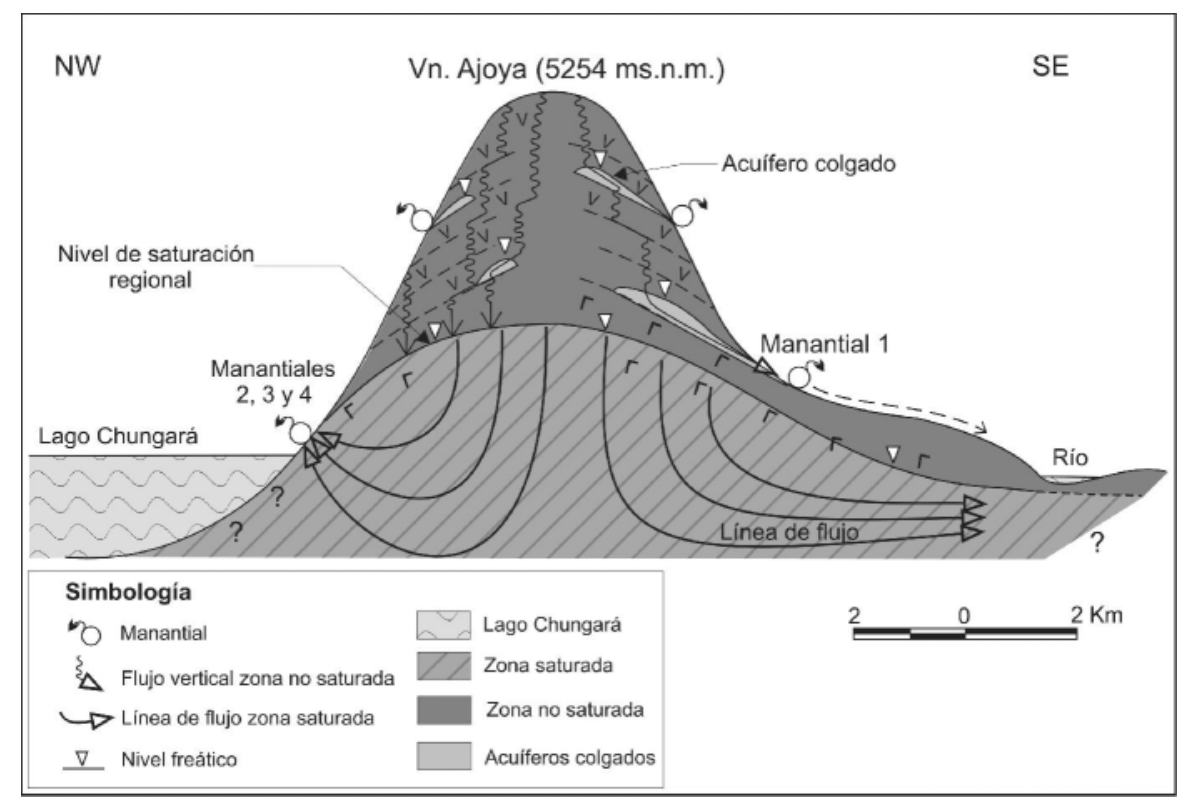

FIG. 12. Perfil hidrogeológico esquemático que muestra el modelo conceptual de circulación del agua subterránea en el volcán Ajoya.

\section{DISCUSIÓN}

Las composiciones isotópicas $\delta^{18} \mathrm{O}$ y $\delta \mathrm{D}$ de las aguas de los manantiales, lagunas de Cotacotani y el lago Chungará muestran que las aguas que conforman la laguna principal de Cotacotani tienen su origen en los aportes de aguas subterráneas recargadas en los edificios volcánicos circundantes y de las aguas del lago Chungará, que circularían subterráneamente por los depósitos volcánicos de brecha hacia las lagunas. La laguna principal de Cotacotani no manifiesta efectos significativos de evaporación, y lo mismo sucede en el caso del río Chungará, en el que los efectos de evaporación de las aguas superficiales parecen ser poco significativos. Además, las aguas de las lagunas de Cotacotani tienen un tiempo de renovación relativamente rápido, debido a que son descargadas superficialmente aguas abajo, hacia el bofedal de Parinacota a razón de $0,44 \mathrm{~m}^{3} \mathrm{~s}^{-1}$ (DGA, 1987), motivo por el cual la incidencia de la evaporación es mínima.

Solamente algunas de las lagunas de Cotacotani que quedan aisladas temporalmente del flujo de circulación, como es el caso de lagunas de los puntos 16 y 17 , muestran composiciones isotópicas distintas y variables en el tiempo que indican efectos de evaporación (Fig. 7a). 
El contenido en tritio obtenido en las aguas de la mayoría de los manantiales indica que la recarga que da origen a los mismos es de sólo algunas decenas de años. Es el caso de las muestras de los manantiales 1,5 y del río Chungará, con contenidos en tritio superiores a las 5 U.T., se estiman tiempos de residencia entre 30 y 40 años. Ello indica que parte de la recarga que da origen a estos manantiales se ha producido con posterioridad a la gran anomalía de tritio, que se registra en las precipitaciones en la década de 1960 como consecuencia de la gran cantidad de pruebas termonucleares realizadas durante este período (Clark y Fritz, 1997). La mayoría de los manantiales y pozos muestreados en el norte de Chile se caracterizan por la ausencia de tritio producido durante las pruebas termonucleares, lo que se ha explicado suponiendo que la recarga que alimenta la mayoría de estos sistemas de agua subterránea es más antigua, o bien que la circulación del agua en los acuíferos es muy lenta. Así, en muestras obtenidas en manantiales y pozos en la Pampa del Tamarugal y el Salar de Atacama (Fritz et al., 1981), en manantiales y cursos de agua superficiales ubicados en cuencas situadas al oeste de la cuenca del lago Chungará (Magaritz et al., 1989), en manantiales y pozos de los márgenes del Salar de Ascotán (Mardones, 1998) y, determinaciones recientes realizadas en manantiales ubicados en las nacientes del río Loa (D. Villablanca, com. oral, Universidad Católica del Norte, 2006), las concentraciones de tritio son inferiores a las 2,8 U.T. y en la gran mayoría de los casos no tienen tritio. En este sentido es posible que los altos contenidos de tritio en los manantiales del área del lago Chungará puedan explicarse por la mayor cantidad de precipitaciones que se registra en esta zona, según lo indican los mapas de isoyetas medias anuales (DGA, 1987) y las imágenes satelitales (Ammann et al., 2001), lo que permitiría una mayor recarga de agua de lluvia en los acuíferos. Así, en las cimas de los volcanes del área del lago Chungará, las precipitaciones superan los $400 \mathrm{~mm}$ anuales, mientras que los lugares indicados anteriormente las precipitaciones en las partes más elevadas alcanzan como máximo los $250 \mathrm{~mm}$ y, frecuentemente, están por debajo de los $200 \mathrm{~mm}$.

La aplicación de los modelos de parámetro agregado para la modelación de los contenidos de tritio de las aguas subterráneas indica que el modelo de flujo de pistón es el que mejor se ajusta para las muestras de agua con mayores concentraciones de tritio. Como las aguas que surgen de estos manantiales lo hacen en el frente de las coladas de lava y en la base de la misma, se puede considerar como modelo conceptual, que la colada actúa como un conducto largo y estrecho, donde el agua es recargada en las cotas más altas, donde las precipitaciones pluviales y nivales son mayores, y circula a lo largo del mismo, hasta alcanzar la zona de descarga en los manantiales (Fig. 13a). Esta situación es muy común en contextos volcánicos, donde la heterogeneidad de los materiales volcánicos genera importantes contrastes de porosidad y permeabilidad de los mismos (Custodio, 1978).

El modelo de flujo de pistón es el que mejor se ajusta al alto contenido de tritio medido en el manantial 5 (8U.T.). Una implicación importante de dicho modelo es que no considera dispersión hidrodinámica en la circulación de las aguas subterráneas. ¿Cómo se puede prescindir del efecto de la dispersión hidrodinámica en el caso de agua que circula por un medio fracturado en una colada de lava reciente muy permeable? Una posible explicación está en el clima árido que rige en la zona y en el régimen de precipitaciones, que sólo son importantes en los meses de verano. Como se deduce de los datos de $\delta^{18} \mathrm{O}$ y $\delta \mathrm{D}$, los episodios de recarga sólo suceden en los meses de primavera-verano, cuando las precipitaciones son suficientemente importantes. También hay que considerar que en algunos años las precipitaciones pueden ser escasas durante los meses de primaveraverano, siendo la recarga muy baja o nula. Por dicha razón se supone que el agua de la recarga se produce de modo irregular y, por lo tanto, pueden producirse distintos pulsos de agua que circulan por la zona no saturada hasta alcanzar la base de la colada de lava y generar un nivel de saturación colgado que comienza su descenso por la base de la colada hasta alcanzar el frente de la misma en el manantial 5 (Fig. 13b). Esta situación también explicaría el comportamiento intermitente que tiene el manantial 5 , según cuentan los habitantes de la zona, y cuya información fue corroborada por los autores durante la campaña de enero de 2004, cuando el manantial estaba seco. De este modo no se produciría dispersión a gran escala y, por lo tanto, no existirían mezclas de aguas con distintas concentraciones de tritio. La validación de este modelo sólo se logrará contando con mayor cantidad de datos de las concentraciones de tritio en este manantial a lo largo del tiempo. 


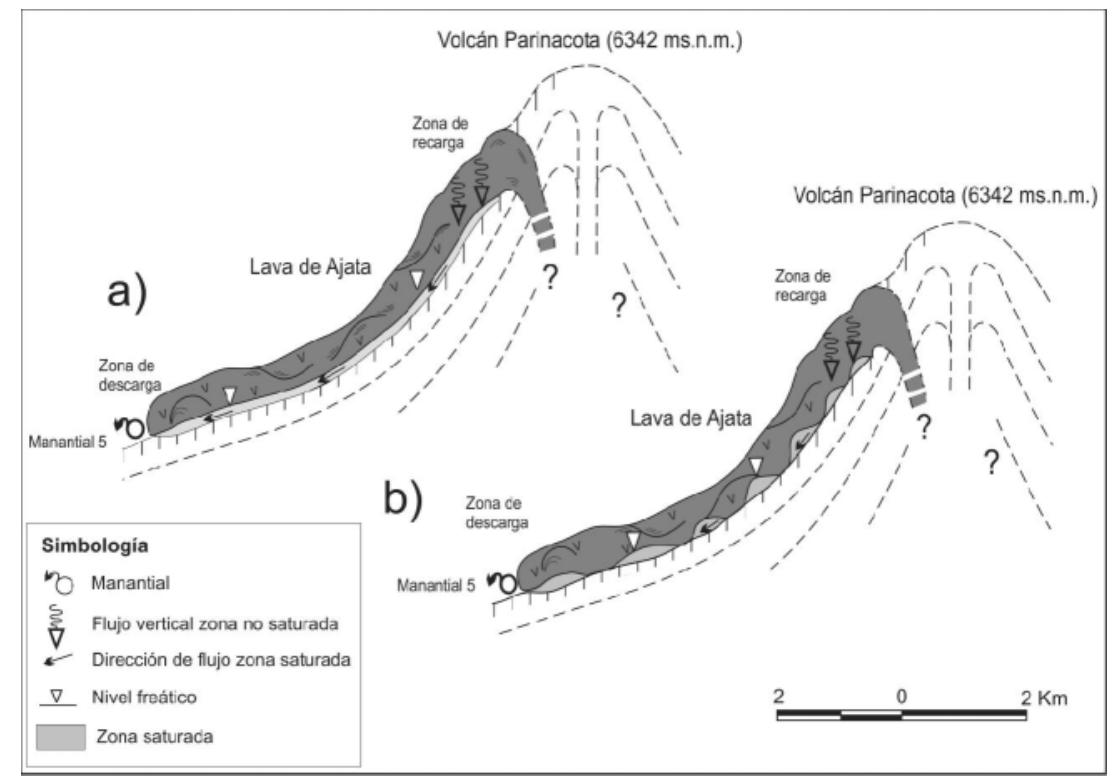

FIG. 13. Esquemas de funcionamiento del manantial 5 desde la zona de recarga hasta la zona de descarga considerando: a. una recarga continua en la parte alta del volcán y b. considerando una recarga intermitente en la parte alta del volcán.

\section{CONCLUSIONES}

- La composición isotópica de $\delta^{18} \mathrm{O}$ y $\delta \mathrm{D}$ de las aguas de las precipitaciones en el área del lago Chungará se caracterizan por ser muy cercanas a la composición isotópica de las precipitaciones que se registran en otras zonas del Altiplano y que han sido caracterizadas a partir de datos isotópicos obtenidos en la ciudad de La Paz.

- La relación de $\delta^{18} \mathrm{O}$ y $\delta \mathrm{D}$ de los cuerpos de agua superficiales y de los manantiales, contrastado con los contenidos de cloruro, permite demostrar la existencia de un flujo de agua subterránea desde el lago Chungará hacia las lagunas de Cotacotani, a través de los depósitos volcánicos brechosos. Las lagunas de Cotacotani, además de recibir aportaciones de agua del lago Chungará, reciben una importante aportación de agua subterránea que ha sido caracterizada isotópicamente por el estudio del agua de los manantiales. Además, la composición química del agua de la laguna principal de Cotacotani puede ser reproducida a partir de la modelación de la mezcla de agua de los manantiales y del lago Chungará. La realización de un balance de masas de las composiciones isotópicas $\delta^{18} \mathrm{O}$ y $\delta \mathrm{D}$ de las aguas de las lagunas de Cotacotani ha permitido calcular que aproximadamente un $58 \%$ del volumen del agua que alimenta las lagunas proviene del lago Chungará, mientras que el $42 \%$ restante lo hace de aportes subterráneos.

- Los contenidos de tritio medidos en las aguas de los manantiales que afloran en los faldeos de los edificios volcánicos del sector, permite demostrar la existencia de una recarga actual a los acuíferos presentes en los edificios volcánicos. Esta recarga tiene su origen en la mayor cantidad de precipitaciones que se registran en esta zona y, mayoritariamente, procede de agua de lluvias de convección que se producen durante los meses de diciembre a marzo.

- La aplicación de distintos modelos de flujo, para explicar los contenidos de tritio obtenidos en los manantiales del sector, permite establecer la existencia de una circulación rápida de las aguas subterráneas en las rocas volcánicas antes de alcanzar las zonas de descarga. Los resultados de la modelación indican que la totalidad de las muestras de agua de los manantiales contienen tritio, que ha sido introducido en el sistema debido a las pruebas termonucleares realizadas a principios de los años sesenta. 
- De la aplicación de modelos agregados para reproducir las concentraciones de tritio medidas en los manantiales, sólo el modelo de flujo de pistón se ajusta a los altos contenidos de tritio. Estos corresponden a manantiales situados en cotas relativamente altas que, posiblemente, están rela- cionados con la descarga de pequeños acuíferos colgados. Por el contrario, los manantiales situados a cotas más bajas, que corresponden a la descarga del agua del nivel de saturación regional, muestran un mejor ajuste con el modelo exponencial.

\section{AGRADECIMIENTOS}

Este estudio ha sido financiado por el proyecto BTE2001-3225 del Ministerio de Ciencia y Tecnología del Gobierno español. Se agradece a los señores G. Cisternas y J. Herreros, de la Corporación Nacional Forestal de la ciudad de Arica, por la colaboración prestada para la realización del trabajo de terreno. Los autores expresan también su agradecimiento al Dr. E. Custodio (Universidad Politécnica de Cataluña), Dr.
B. Keller (Andalué Ambiental Ltda., Chile) y a un árbitro anónimo, por las valiosas sugerencias que han permitido mejorar sustancialmente este artículo. Se agradece al editor M. Suárez por todas las gestiones realizadas para la publicación de este artículo. También a R.O. Gibert, N. Herrero, B. Ordenes y A. Álvarez por su trabajo en las campañas de laboratorio y terreno.

\section{REFERENCIAS}

Ammann, C.; Jenny, B.; Kammer, K.; Messerli, B. 2001. Late Quaternary Glacier response to humidity changes in the arid Andes of Chile (18-29 $\mathrm{S})$. Paleogeography, Paleoclimatology, Paleoecology 172 (3-4): 313-326.

Aravena, R.; Susuki, O.; Peña, H.; Pollastri, A.; Fuenzalida, H.; Grilli, A. 1999. Isotopic composition and origin of the precipitation in Northern Chile. Applied Geochemistry 14 (4): 411-422.

Clark, I.; Fritz, P. 1997. Environmental Isotopes in Hydrogeology, Lewis Publishers 328 p. New York.

Clavero, J.E.; Sparks, R.; Huppert, H. 2002. Geological constraints on the emplacement mechanism of the Parinacota debris avalanche, northern Chile. Bulletin of Volcanology 64: 40-54.

Clavero, J.E.; Sparks, S.J.; Polanco, E.; Pringle, M. 2004. Evolution of Parinacota Volcano, Central Andes, Northern Chile. Revista Geológica de Chile 31 (2): 317-347.

Custodio, E. 1978. Geohidrología de terrenos e islas volcánicas. Instituto de Hidrología, Centro de Estudios Hidrográficos: 303 p. Madrid.

Custodio, E.; Llamas, M.R. (Editores). 1983. Hidrología Subterránea. Editorial Omega: 2350 p. Barcelona.

Dirección General de Aguas (DGA). 1987. Balance Hídrico de Chile. Ministerio de Obras Públicas: 24 p. Santiago.

Dorador, C.; Pardo, R.; Vila, I. 2003. Variaciones temporales de parámetros físicos, químicos y biológicos de un lago de altura: el caso del lago Chungará. Revista Chilena de Historia Natural 76 (1): 15-22.
Fritz, P.; Suzuki, O.; Silva, C.; Salati, E. 1981. Isotope hydrology of groundwaters in the Pampa del Tamarugal, Chile. Journal of Hydrology 53 (1-2): 161184.

Gonfiantini, R. 1986. Environmental isotopes in lake studies. In Handbook of Environmental Isotope Geochemistry (Fritz, P.; Fontes, J.Ch.; editores). Elsevier 2: 113-168. Amsterdam.

Gonfiantini, R.; Roche, M.; Olivery, J.; Fontes, J.; Zuppi, G. 2001. The altitude effect on the isotopic composition of tropical rains. Chemical Geology 181 (1-4): 147-167.

Iglesias, M. 1999. Caracterización hidrogeoquímica del flujo del agua subterránea en El Abalario, Doñana, Huelva. Tesis Doctoral (Inédito), Universidad Politécnica de Cataluña: 254 p. Barcelona.

Katsui, Y.; González-Ferrán, O. 1968. Geología del área neovolcánica de los Nevados de Payachata. Universidad de Chile, Facultad de Ciencias Físicas y Matemáticas, Departamento de Geología, Publicación 29: 61 p. Santiago.

Klohn, W. 1972. Hidrografía de las zonas desérticas de Chile. Naciones Unidas, Proyecto CHI-535: 188 p. Santiago.

Lambán, J. 1998. Estudio de la recarga y del funcionamiento hidrogeológico de la Unidad Anoia (Cordillera Prelitoral Catalana). Tesis Doctoral (Inédito), Universidad Politécnica de Cataluña: 207 p. Barcelona.

Magaritz, M.; Aravena, R.; Peña, H.; Suzuki, O.; Grilli, A. 1989. Water chemistry and isotope study of streams and springs in northern Chile. Journal of Hydrology 
108: 323-341.

Malozewski, P.; Zuber, A. 1982. Determining the turnover time of groundwater systems with the aid of environmental tracers. Journal of Hydrology 57: $207-$ 231.

Mardones, L. 1998. Flux et évolution des solutions salines dans les systèmes hydrologiques des salars d'Ascotan et d'Atacama. Thèse de Doctorat (Non publié), Université Paris XI Orsay: 203 p.

Mladinic, P.; Quintana, E.; Hrepic; N. 1984. Parámetros físicos y químicos de las aguas de los lagos Chungará y Cotacotani, I Región (Chile). Idesia 8: 5-17.

Montgomery, E.; Rosko, M.; Castro, S.; Keller, B.; Bevacqua, P. 2003. Interbasin underflow between closed Altiplano Basins in Chile. Groundwater 41 (4): 523-531.

Montti, S.; Henríquez, H. 1970. Interpretación hidrogeológica de la génesis de salares y lagunas del Altiplano Chileno. In Congreso Geológico Chileno, No. 2, Actas 3: G69-G81. Arica.

Mühlhauser, H.; Hrepic, N.; Mladinic, P.; Montecino, V.; Cabrera, S. 1995. Water quality and limnological features of a high altitude Andean lake, Chungará, in northern Chile. Revista Chilena de Historia Natural 68: 341-349.

Órdenes, B. 2004. Estudio hidrogeoquímico del área del lago Chungará y de las lagunas de Cotacotani, I Región de Tarapacá, Chile. Memoria de Título (Inédito), Universidad Católica del Norte, Departamento de Ciencias Geológicas: 111 p.

Parkhurst, D. 1995. User's guide to PHREEQC- a computer program for speciation, reaction path, advectivetransport, and inverse geochemical calculations. United States Geological Survey, Water-Resources Investigations Report 95-4227: 1-143.

Plata, A. 1994. Composición isotópica de las aguas subterráneas de la Península Ibérica. Centro de Estudios y Experimentación de Obras Públicas: 139 p. Madrid.

Richter, J.; Szymczak, P.; Jordan, H. 1992. A computer program for the interpretation of isotope hydrogeologic data. Tracer Hydrology. In Proceeding of the $6^{\text {th }}$ Int. Symp. On water tracing: 461-462. Karlsruhe.

Risacher, F.; Alonso, H.; Salazar, C. 1999. Geoquímica de aguas en cuencas cerradas: I, II, II Regiones-Chile. Ministerio de Obras Públicas 1: 209 p. Chile.

Risacher, F.; Alonso, H.; Salazar, C. 2003. The origin of brines and salts in Chilean salars: a hydrochemical review. Earth-Science Reviews 63 (3-4): 249-293.

SERNAGEOMIN. 2002. Mapa Geológico de Chile. Servicio Nacional de Geología y Minería, Carta Geológica de Chile, Serie Geológica Básica 75, 1 mapa en 3 hojas, escala 1:1.000.000. Santiago.

Takaoka, N.; Mizutani, Y. 1987. Tritiogenic ${ }^{3} \mathrm{He}$ in groundwater in Takaoka. Earth and Planetary Science Letters 85 (1-3): 74-78.

Thompson, L. 2000. Ice core evidence for climate change in the tropics: implications for our future. Quaternary Science Reviews 19 (1-5): 19-35.

Thompson, L.; Thompson, E.; Henderson, K. 2000 Icecore paleoclimate records in tropical South America since the Last Glacial Maximum. Journal of Quaternary Science 15 (4): 377-394.

Valero, B.; Delgado, A.; Navas, A.; Edwards, L.; Schwalb, A.; Ratto, N. 2003. Patterns of regional hydrological variability in central-southern Altiplano $\left(18^{\circ}-26^{\circ} \mathrm{S}\right)$ lakes during the last 500 years. Palaeogeography, Palaeoclimatology, Palaeoecology 194 (1-3): 319338.

Wörner, G.; Harmon, R.S.; Davidson, J.; Moorbath, S.; Turner, D.L.; McMillan, N.; Nye, C.; López-Escobar, L.; Moreno, H. 1988. The Nevados de Payachata volcanic region $\left(18^{\circ} \mathrm{S} / 69^{\circ} \mathrm{W}, \mathrm{N}\right.$. Chile): I. Geological, geochemical, and isotopic observations. Bulletin of Volcanology 50: 287-303. 